\title{
Next Generation Gas Turbine (NGGT) Systems Study
}

\author{
Final Report
}

Prepared for: US Department of Energy

National Energy Technology Laboratory

Morgantown, WV 26507-0880

Prepared by: General Electric Company

GE Power Systems

Schenectady, NY. 12345

Issue Date: December 5, 2001

DOE Contract No. DE-AC26-00NT40846 


\section{DISCLAIMER}

This report was prepared as an account of work sponsored by an agency of the United States Government. Neither the United States Government nor any agency thereof, nor any of their employees, makes any warranty, express or implied, or assumes any legal liability or responsibility for the accuracy, completeness, or usefulness of any information, apparatus, product, or process disclosed, or represents that its use would not infringe privately owned rights. Reference herein to any specific commercial product, process, or service by trade name, trademark, manufacturer, or otherwise does not necessarily constitute or imply its endorsement, recommendation, or favoring by the United States Government or any agency thereof. The views and opinions of authors expressed herein do not necessarily state or reflect those of the United States Government or any agency thereof. Information judged to be General Electric Company Confidential and Proprietary has been edited from this Final Report, and so denoted by the letter " $\mathrm{C}$ " where pertinent. This information is available for inspection by the appropriate US government contracting Program Manager and Agency upon request. 


\section{ABSTRACT}

Building upon the 1999 AD Little Study, an expanded market analysis was performed by GE Power Systems in 2001 to quantify the potential demand for an NGGT product. This analysis concluded that improvements to the US energy situation might be best served in the near/mid term (2002-2009) by a "Technology-Focused" program rather than a specific "Product-Focused" program. Within this new program focus, GEPS performed a parametric screening study of options in the three broad candidate categories of gas turbines: aero-derivative, heavy duty, and a potential hybrid combining components of the other two categories. GEPS's goal was to determine the best candidate systems that could achieve the DOE PRDA expectations and GEPS's internal design criteria in the period specified for initial product introduction, circa 2005. Performance feasibility studies were conducted on candidate systems selected in the screening task, and critical technology areas were identified where further development would be required to meet the program goals. DOE PRDA operating parameters were found to be achievable by 2005 through evolutionary technology. As a result, the study was re-directed toward technology enhancements for interim product introductions and advanced/revolutionary technology for potential NGGT product configurations.

Candidate technologies were identified, both evolutionary and revolutionary, with a potential for possible development products via growth step improvements. Benefits were analyzed from two perspectives: 1) What would be the attributes of the top candidate system assuming the relevant technologies were developed and available for an NGGT market opportunity in 2009/2010; and 2) What would be the expected level of public benefit, assuming relevant technologies were incorporated into existing new and current field products as they became available. Candidate systems incorporating these technologies were assessed as to how they could serve multiple applications, both in terms of incorporation of technology into current products, as well as to an NGGT product. In summary, potential program costs are shown for development of the candidate systems along with the importance of future DOE enabling participation.

Three main conclusions have been established via this study: 1) Rapid recent changes within the power generation regulatory environment and the resulting "bubble" of gas turbine orders has altered the timing and relative significance associated with the conclusions of the ADL study upon which the original DOE NGGT solicitation was based. 2) Assuming that the relevant technologies were developed and available for an NGGT market opportunity circa 2010, the top candidate system that meets or exceeds the DOE PRDA requirements was determined to be a hybrid aero-derivative/heavy duty concept. 3) An investment by DOE of approximately $\$ 23 \mathrm{MM} /$ year to develop NGGT technologies near/mid term for validation and migration into a reasonable fraction of the installed base of GE F-class products could be leveraged into a \$1.2B Public Benefit, with greatest benefits resulting from RAM improvements. In addition to the monetary Public Benefit, there is also significant benefit in terms of reduced energy consumption, and reduced power plant land usage.

GEPS recommends that technologies deemed applicable to an NGGT product should be developed in this near/mid time frame, anticipating a delayed new product need circa 2010. During this interim period, many, if not all, of these technologies could be available for demonstration testing on various existing products, thereby mitigating risks associated with the longer-term incorporation of these technologies into an NGGT product. This technology-focused approach provides benefits not originally envisioned by DOE and further provides a roadmap for the validation and maturation of NGGT technologies. 


\section{Table of Contents}

Disclaimer .............................................................................................................................. 2

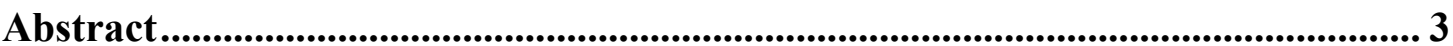

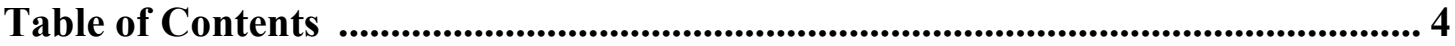

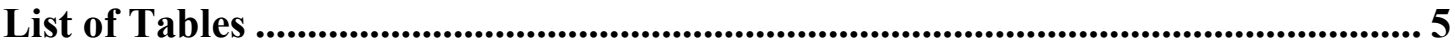

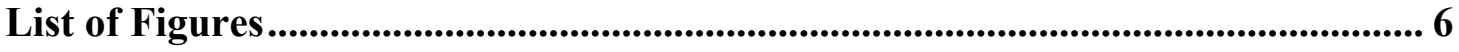

Acronyms ........................................................................................................................... 7

Executive Summary ........................................................................................................ 9

Task 1 : Market Analysis..................................................................................................... 11

Task 2 : Options Screening.................................................................................23

2.1 Quantifying The Critical to Quality Parameters ......................................23

2.2 Complete the Quality Function Deployment Matrix ..............................31

Task 3 : Detailed Analysis of Candidate Systems.................................................35

3.1 Detailed Analysis of Candidate Systems ................................................35

3.2 Reliability, Availability, and Maintainability Assessment ....................37

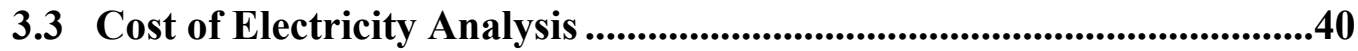

3.4 Risk Analysis and Decision ......................................................... 42

Task 4 : Enabling Technologies .......................................................................... 47

4.1 Identification of Technology Needs ............................................................47

4.2 Development of Roadmap for Development of Technology Needs ......50

Task 5 : Analysis of Benefits.............................................................................52

5.1 Analysis of Support for Vision 21 ..................................................52

5.2 Analysis of Public Benefits ................................................................54

Task 6 : Ability to Serve Multiple Users .......................................................60

Task 7 : Cost Plan for System Development.............................................................. 62

References ......................................................................................................................... 64

Appendicies ................................................................................................................................ 65 


\section{List Of Tables}

Table 1.1: Internal QFD Format and Process ............................................................15

Table 1.2: NGGT Survey - Customer Candidate Profile ......................................17

Table 2.1.1: State of the Art Engines ........................................................................24

Table 2.1.2: Near/Mid Design Targets for NGGT ..............................................25

Table 2.1.3: Key Features of Aeroderivatrive Concepts ............................................27

Table 2.1.4: Key Design Parameters for NGGT Concept ....................................29

Table 2.2.1: NGGT Concept Attributes. ..........................................................32

Table 2.2.2: Results of 3DQFD showing Scores of Candidate Systems...................33

Table 2.2.3: Downselected Aero, Hybrid, and Heavy Duty NGGT Concepts ..... 34

Table 3.1.1: Performance Characteristics of Downslected Candidates ..................35

Table 5.2.1: Societal Benefits Assumptions.........................................................55

Table 5.2.2: Primary Savings with NGGT Program.................................................56

Table 5.2.3: Emissions Savings With NGGT Program .......................................56

Table 5.2.4: Heat Rate Needed to Displace Coal-Fired Capacity ............................57

Table 5.2.5: Public Benefits of NGGT Technologies in F Fleet.............................58

Table 6.1: Expected Competiveness of NGGT. .................................................60

Table 7.1: Development Costs for Downselected Candidate Concepts. .................62

Table 7.2: Spending Profile for Aero Derivative and Hybrid Programs ...............63

Table 7.3: Spending Profile for Heavy Duty 2 Shaft Engine Program .................63 


\section{List of Figures}

Figure 1.1: Comparison of Market Study Assumptions and Conclusions.............12

Figure 1.2: Internal QFD Survey Results

Figure 1.3: Customer Market Survey Results - Producer Types...........................18

Figure 1.4: NGGT User Profiles ...........................................................................19

Figure 1.5: NGGT Customer Survey Results - CTQ Rankings ............................20

Figure 1.6: NGGT Customer Barriers to Entry .................................................21 


\section{$\underline{\text { Acronyms }}$}

3DQFD - Three Dimensional Quality Flowdown Deployment Matrix (patent pending)

ADL - Arthur D. Little, Inc.

CBM - Condition Based Monitoring

CC - Combined Cycle

CHP - Combined Heat and Power

CMC - Ceramic Matrix Composites

COE - Cost of Electricity

CTQ - Critical To Quality

DLN - Dry Low NOx

DOD - US Department of Defense

DOE - US Department of Energy

EBC - Environmental Barrier Coating

EUPG - Electric Utility Power Generator

FERC - Federal Energy Regulatory Commission

GE - General Electric Company

GEPS - GE Power Systems

GT - Gas Turbine

GW - Giga Watts

HHV - Higher Heating Value

HR - Heat Rate

I/C - Intercooler

ICAD - Inter Cooled Aero Derivative

IPG - Industrial Power Generator

IPP - Independent Power Producer

LHV - Lower Heating Value

LPC - Low Pressure Compressor

LPT - Low Pressure Turbine

M\&D - Monitoring and Diagnostics

MGTP - Multi Generational Technology Plan

MMBTU - Million British Thermal Units

MW - Mega Watts

NERC - National Energy Regulatory Commission

NETL - National Energy Technology Laboratory

NGGT - Next Generation Gas Turbine

NOx - Nitrogen Oxides

O\&M - Operations and Maintenance

OPR - Operating Pressure Ratio

P - Combustor operating pressure in atm

PIV - Particle Image Velocimetry

PPM - Parts per million

PRDA - Program Research and Development Announcement

Q - Total heat release in combustor

QFD - Quality Flowdown Deployment matrix

RAM - Reliability, Availability and Maintainability 
RH - Relative Humidity

RTO - Regional Transmission Organizations

S - DLE Combustor design severity parameter

SC - Simple Cycle

SPRINT - SPRay INTercooling

TVC - Trapped Vortex Combustor 


\section{Executive Summary}

\section{$\underline{\text { INTRODUCTION }}$}

In their 1999 Annual Energy Outlook, the DOE Energy Information Administration (EIA) projected a need for 124 Gigawatts (GW) of new turbine capacity in the U. S. by the year 2020, due to a combination of economic growth, and the retirement of older, less efficient, gas and oil-fired generating capacity. During the past five years, gas turbines have become the dominant power generation technology in the U.S., as their versatility has allowed them to serve a variety of applications. Gas turbine technology has proven to be extremely effective in meeting performance, cost, and environmental standards.

In a DOE-sponsored study performed by A.D. Little conducted in 1999, it was projected that a significant market for advanced technology, mid-size (30 MW-150 MW) gas turbines would develop to serve the projected increase in power demand. These units would serve the on-peak and intermediate load demands of power producers, and would operate between 500 and 5000 hours per year, depending on power demand. These machines would need to be capable of up to 400 starts per year, with high reliability and improved life parameters, have reduced emissions, multiple fuel capability, an increase in gas turbine efficiency, and a consequent reduction in life cycle cost of electricity.

\section{GE POWER SYSTEMS STUDY RESULTS}

An expanded market analysis, building upon that completed in 1999 by AD Little, was performed by GE Power Systems in 2001 in order to quantify the potential demand for a potential NGGT product. This analysis concluded that improvements to the US energy situation might be best served in the near/mid term (2002-2009) by a "Technology-Focused" program rather than a specific "ProductFocused" program. GEPS recommends that technologies deemed applicable to an NGGT product should be developed in this near/mid time frame, anticipating a delayed new product need circa 2010. During this interim period, many, if not all, of these technologies could be available for demonstration testing on various existing products. This approach would provide Public Benefits not originally envisaged by DOE.

Within the new technology program focus, GE Power Systems performed a parametric screening study of options in the broad three candidate categories of gas turbines: aero-derivative, heavy duty, and a potential hybrid combining components of the other two categories, in order to determine the engine configuration that best meets the DOE PRDA operating parameters, and GE's internal design criteria. Performance feasibility studies were performed on the candidate systems selected in the screening task, and limited technology areas were identified where further development would be required to meet the goals. In fact, the DOE PRDA operating parameters could be achieved by 2005 with only evolutionary technology. This conclusion further supports the GEPS position and strategy. It was therefore decided to carryon the study addressing the original 2005 product, best case 2010 product, and interim technology introduction scenarios.

The best candidate systems that could achieve the DOE PRDA goals in the period specified for initial product introduction; circa 2005, were identified by applying Six Sigma methodology via a 3D QFD 
tool in Task 2. These candidate systems were assessed in more detail in Task 3 . Those systems that could achieve the DOE specified performance parameters in the period specified for initial product introduction; circa 2005, were then identified.

Candidate technologies, both evolutionary and revolutionary that could be developed and eventually transitioned into the candidate products as growth step improvements were identified in Task 4.

Benefits were analyzed in Task 5 to assess the support for Vision 21. The configurations assessed, and the enabling technologies identified, are scalable to Vision 21 combined cycle power plants and are amenable to the modular, building block paradigm that is central to Vision 21 wherein power, chemicals, and fuel-conversion technology modules are integrated into systems that achieve the needed level of performance at affordable costs. Additionally, an analysis of public benefits was made from two perspectives:

- Assuming the relevant technologies were developed and available for an NGGT market opportunity in 2009/2010, what would be the attributes of the top candidate system?

- Assuming relevant technologies were incorporated into existing new and current field products as they became available, what would be the level of public benefit expectation?

Candidate systems were assessed in Task 6 as to how they could serve multiple users, both in terms of current product incorporations of technology and into the candidate systems. Task 7 then showed potential program costs for development of the candidate systems, and also how this technology development initiative could be enabled by DOE participation.

\section{CONCLUSIONS}

Three main conclusions were established via this study.

- Firstly, rapid recent change within the power generation regulatory environment and the resulting "bubble" of gas turbine orders has altered the timing and relative significance associated with the conclusions of the ADL study upon which the original DOE NGGT solicitation was based.

- Secondly, nonetheless, and assuming that the relevant technologies were developed and available for an NGGT market opportunity circa 2010, the top candidate system that meets or exceeds the DOE PRDA requirements was herein determined to be a hybrid aeroderivative/heavy duty concept.

- Thirdly, an investment by DOE of about $\$ 23 \mathrm{MM} /$ year for four years could be leveraged into a \$1.2B Public Benefit by developing NGGT technologies for near $/ \mathrm{mid}$ term validation and migration into a reasonable fraction of the installed base of GE F-class products, with the greatest benefits resulting from RAM improvements. Not only is there a monetary Public Benefit, but there is also a benefit in terms of reduced energy consumption, emissions, and reduced power plant land usage.

This technology-focused approach provides benefits not originally envisaged by the DOE. Further, it provides a roadmap for the validation and maturation of NGGT technologies that mitigates the risk associated with the longer-term incorporation of these technologies into an NGGT product. 


\section{Task 1: Market Analysis}

\section{TASK OBJECTIVE:}

The contractor shall conduct a thorough system study for a Next Generation Gas Turbine. This machine will be in the 30-150 MW power range, and have performance characteristics as defined in DOE PRDA DE-RA26-00FT40721. Heavy duty, aero-derivative, and hybrid machines shall be analyzed for the time period 2003-2020 for the U.S. and world market. Results of the market analysis for gas turbines that meet these criteria shall be included in the Interim Topical Report.

The market analysis shall include interviews and assessments with at least 10 of the potential major customers for contractor's Next Generation Gas Turbines systems. This analysis shall cover the stated time frame duty for the machine introduction and operation to the year 2020, and shall include segregation of the market application (industrial, distributed generation, merchant plant, repowering of coal/gas plants, military markets etc).

\section{INTRODUCTION:}

Arthur D. Little, Inc. (ADL) performed a strategic evaluation of the mid-sized gas turbines for the U. S. Department of Energy in 1998-1999. ${ }^{1}$ The DOE commissioned this study primarily to assess the market potential for a Next Generation Gas Turbine (NGGT), or in ADL's terminology an "Advanced Mid-sized Gas Turbine".

This task describes the results of GE PS's review of the ADL study, and identifies the specific actions GE Power Systems (GEPS) took to update the market view for a 30-150MW+ NGGT type machine having the performance characteristics defined in DOE PRDA DE-RA26-00FT40721 in the 2005 time frame. It will also provide a confirmation of GE's market analysis based on a survey with 10 energy generators.

\section{RESULTS AND DISCUSSION:}

\section{Domestic Market}

An Interim Topical report describing the GEPS review of the ADL study: "Strategic Evaluation of Needs and Opportunities for U.S. Mid-Sized Gas Turbines in Intermediate Load Applications", and the identification of specific actions GEPS intended to take to update the market view, was provided to DOE-NETL on 15 August, 2000. GE Power Systems generally found the methodology and approach used by ADL to be sound, however several important changes in market place dynamics had taken place since the 1999 ADL analysis. Current oil and natural gas prices are almost twice as high as those considered in the ADL study. Changes in fuel price have significant impact on market penetration analyses for gas turbine based technologies. Additionally, the recent market for new capacity additions in the US has been more robust than had been assumed in the ADL analysis. This large influx of new capacity additions will significantly change the operational landscape under which new technologies will be operating. Further, whereas ADL envisioned significant

1 "Strategic Evaluation of Needs and Opportunities for U.S. Mid-Sized Gas Turbines in Intermediate Load Applications", A. D. Little, Inc., April 13, 1999. 
displacement driven by high electricity peak prices, GEPS foresees competitive pricing behavior contributing to low NGGT displacement potential. Finally, the impact of the "new economy" and internet-driven load growth not specifically addressed by the ADL analysis needs to be considered in any US market load growth scenarios in evaluating market viability. These significant changes are continuing in the power industry, and information is available today that was not available at the time of the ADL study.

\section{Displacement Potential}

Figure 1.1 captures the salient differences in perspective, and the resulting differences in market forecast, between the ADL and GEPS market studies. ADL's 1999 forecast of high displacement potential was based on high peak electricity prices and low penetration of CC generation capacity. GEPS's assumptions of competitive pricing and high $\mathrm{CC}$ penetration result in significantly lower displacement potential. Domestic displacement opportunities will only exist in areas that were somewhat under-built, and most, if not all, opportunities will be consumed by announced projects using today's technology equipment. In particular, GEPS's projected displacement potential ranges from zero, to the lower range ADL's estimate of $32 \mathrm{GW}$.

\section{A. D. Little 4/99}

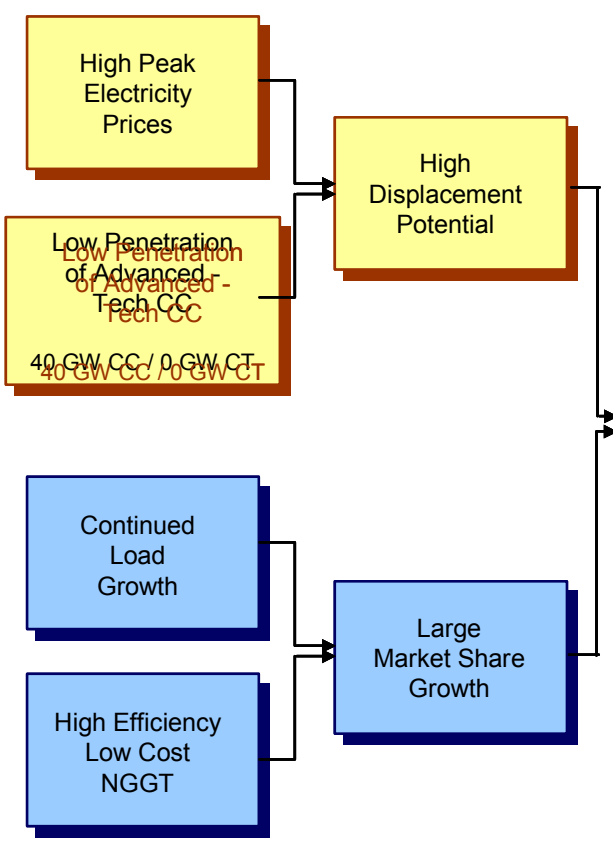

\section{GEPS $12 / 00$}

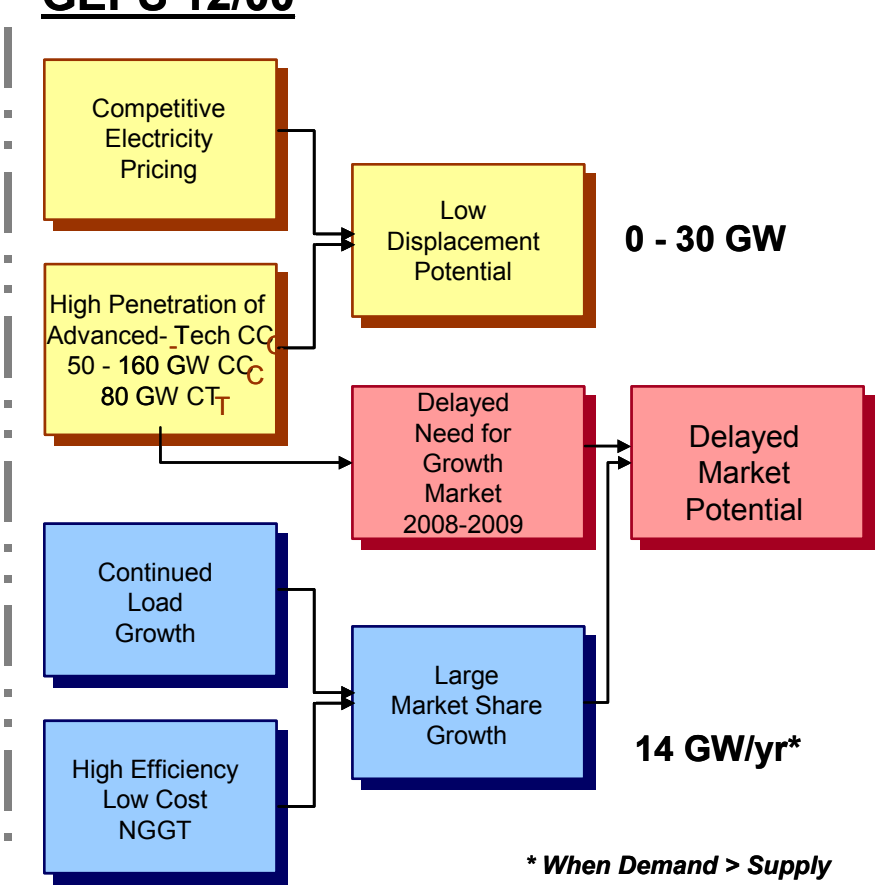

\section{Recent Power Industry Activity Leads to Different Conclusions in 2001 than Reached by A. D. Little in 1999}

Figure 1.1: Comparison of Market Study Assumptions and Conclusions 


\section{GE Power Systems}

\section{Load Growth}

Both the ADL and the GEPS market studies anticipate some growth in load demand, although the magnitude and timing for this growth varies significantly between the two studies. The ADL study projected immediate, albeit modest levels of load growth. GEPS anticipates that the recent and current installation of new CC generation capacity will culminate in a period of equilibrium between load growth demand and supply. This will delay the need for additional capacity until approximately 2008 - 2009. Once load demand again exceeds supply, around 2009, GEPS anticipates that load growth will be approximately $14 \mathrm{GW}$ / year - a much more robust growth rate compared with the ADL projection of at most, $3.5 \mathrm{GW} /$ year.

\section{World Market}

An extrapolation to the World Market of the GEPS/ADL US market analysis results was accomplished using GEPS current business forecast as a guide for 2009-2020 in terms of economics and 2020 generation potentials. This included integration of current market information such as: fuel forecasts, deregulation status, nuclear expansion, environmental, and economic forecasts from industry data. This subjective assessment was developed on a country-by-country basis including price and availability of fuels and past technology preferences. The assessment suggested that the first commercial opportunities for an NGGT product might in fact be overseas.

Many regions in the world, in addition to North America, have been installing gas turbine based power plants at an increasing pace over the past 20 years. Asia and Europe, with significant growth in both GT and Combined Cycle plants, and to a lesser extent the Middle East and Latin America where GT plant additions have been dominating, have seen the most significant growth. The major reasons for this development have been the availability and price level of natural gas, and the lower environmental emission levels offered by gas turbine systems. These, coupled with rapidly advancing gas turbine technology, have allowed natural gas based gas turbines and combined cycle power plants to serve in midrange and base load operating duty more economically than conventional coal based steam power plants.

The NGGT advanced technology gas turbines will likely participate in the future generation mix of many countries. The purpose of the GEPS forecast of the international power generation market penetration of the NGGT technology was to provide an estimate for the market penetration of the NGGT gas turbines.

The forecast was done as an incremental forecast to GEPS's traditional worldwide power generation forecast. Significant growth in gas turbine based generating plants, but no additional gas turbine penetration due to the NGGT technology, was assumed. The NGGT technology was assumed to pick up more of the simple cycle market than the combined cycle market.

There are no rigorous forecasting tools available to perform this type of analysis, so the results are based on trends and estimated impacts of parameters such as: predicted electricity growth rates, regional gas availability and price levels, regional availability and trends of application of coal burning technologies, gas turbine efficiency levels, and traditional acceptance level of new technologies. The time period for this assessment, 2005 through 2020, is a significantly longer time period than GEPS's power generation forecast period. Hence, the years from 2005 to 2020 are an extrapolation. 
The total generation additions, not currently on order, for the $2005-2020$ period are projected to approximately $2000 \mathrm{GW}$. This total includes fossil-fired and nuclear-fired steam turbine plant. Large hydro plants, combined cycle plants, simple cycle gas turbine plants and other miscellaneous plants. The "other" category includes solar, wind, geothermal, small hydro and reciprocating engines.

A forecast was made for gas turbine and combined cycle plant additions (in GW) per Region encompassing Africa, Asia, Europe, Latin America, and the Middle East for the time frame 2005 2020. The total for these plant types is $1000 \mathrm{GW}$, or about one half of the total of $2000 \mathrm{GW}$. It should be noted that combined cycle plants normally would have two thirds of the capacity in gas turbines and one third in steam turbine capacity so the forecasted total gas turbine additions are then about $38 \%$ of the total additions.

The forecasted portion of the total GT and CC MW that may go to NGGT technology was then assessed per Region over the same time frame: 2005 -2020. On a comparative regional basis, the NGGT technology may capture between 25 and $45 \%$ of the gas turbine GW's, and between 5 and 15 $\%$ of the combined cycle GW's. The size chosen for the NGGT technology of $30-150 \mathrm{MW}$ is probably the most significant driver behind this estimate, and will likely allow a higher penetration in the simple cycle gas turbine plants than for the combined cycle plants.

A follow-on confirmation of the studies subsequent market segmentation and projection results, which have initially been reviewed with our own internal GEPS regional sales force, has been reviewed with a select group of energy generators to further identify and quantify potential product characteristics.

In January of 2001, an internal Quality Functional Deployment (QFD) was performed while surveying 20 members of the GE Power Systems sales organization along with 8 other members of the NGGT Team. The QFD or sales survey identified product characteristics that are key to customer purchase decisions. These product characteristics (found in Table 1.1) or "critical to quality" (CTQs) - "Customer Wants" were ranked by the GEPS multi-functional NGGT team for a number of market segments including EUPG, IPP, SC and CC applications based on market data available at the time. Members of the GEPS Sales organization also ranked the CTQs. The results of those surveys are found in Figure 1.2.

\section{Customer Survey}

Inputs from the sales managers were used to develop the customer survey as well as to identify key customers for the survey. A summary of the NGGT survey candidates, which represent a cross section of power generation customers from the various segments around the world, is listed in Table 1.2 .

GEPS Account Executives sent letters to key customers inviting them to participate in the NGGT survey. Returned results from at least 10 customers been tabulated and are contained in Figure 1.3. A compilation of the User Profiles is provided in Figure 1.4 and 1.5. The survey is composed of two formats. The first format is a questionnaire designed to better understand the segments that the customers serve, buying behaviors and buying constraints. The second format is a QFD matrix that, like the one that was developed for GEPS internal QFD, allows the customer to vote, using a total of 80 points, for their most-desired CTQs. 
Table 1.1: Internal QFD Format and Process

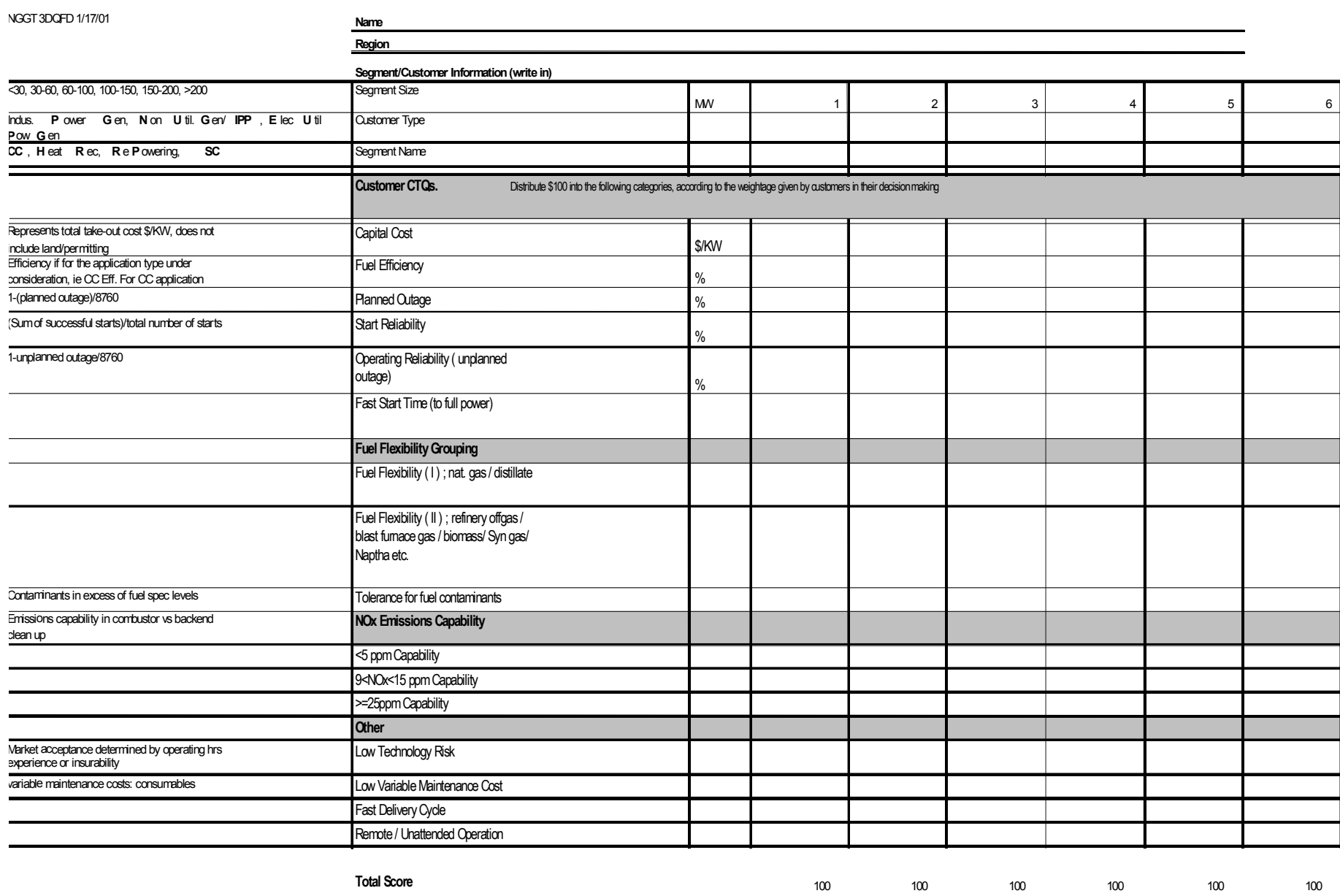

- 28 GE participants

- 20 sales personnel representing broad cross section of the world power generation segments

- Voted on 16 key market CTQ's

- Voting was weighted100 Points could be distributed across 16 CTQ's in any fashion 
Figure 1.2: Internal QFD Survey Results

- 2 sets of data points; Sales vs. NGGT Team

- 3 Segments; 30 - 60 MW, 60 - 100 MW \& 100 150 MW

- GE perception Is that installed capital cost and fuel efficiency are key customer CTQs

- High reliability, availability and maintainability levels are customer entitlements

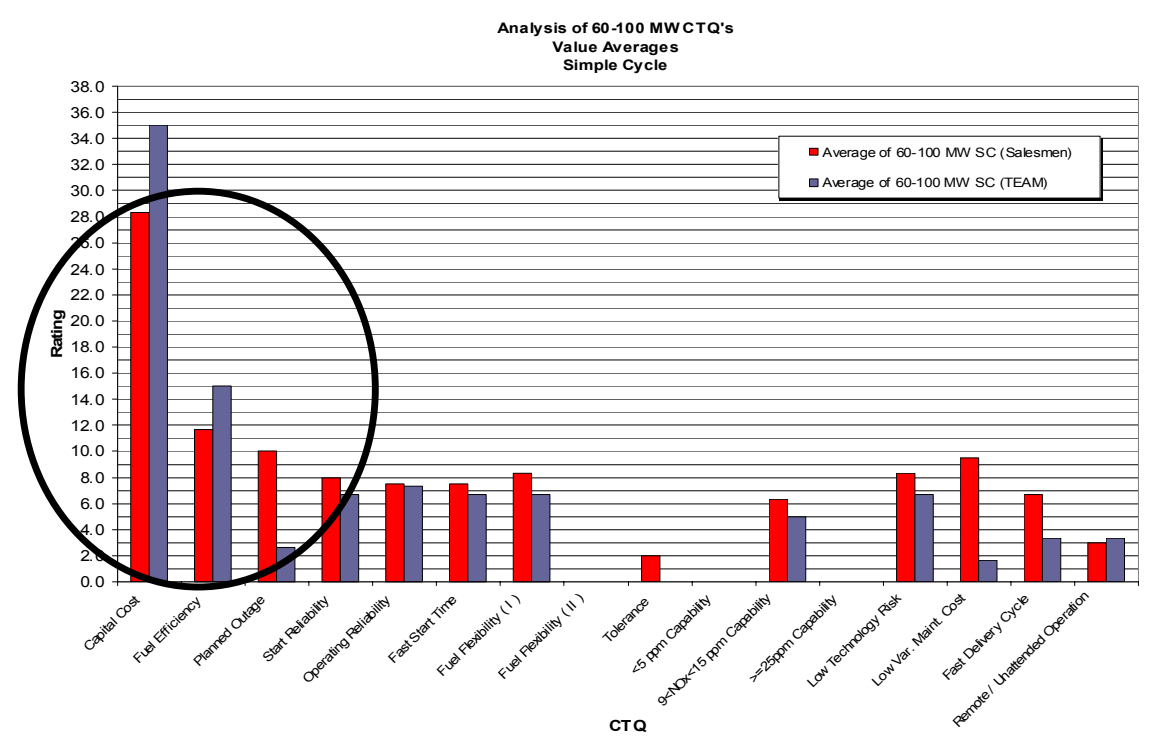

Contract DE-RA26-00FT40721

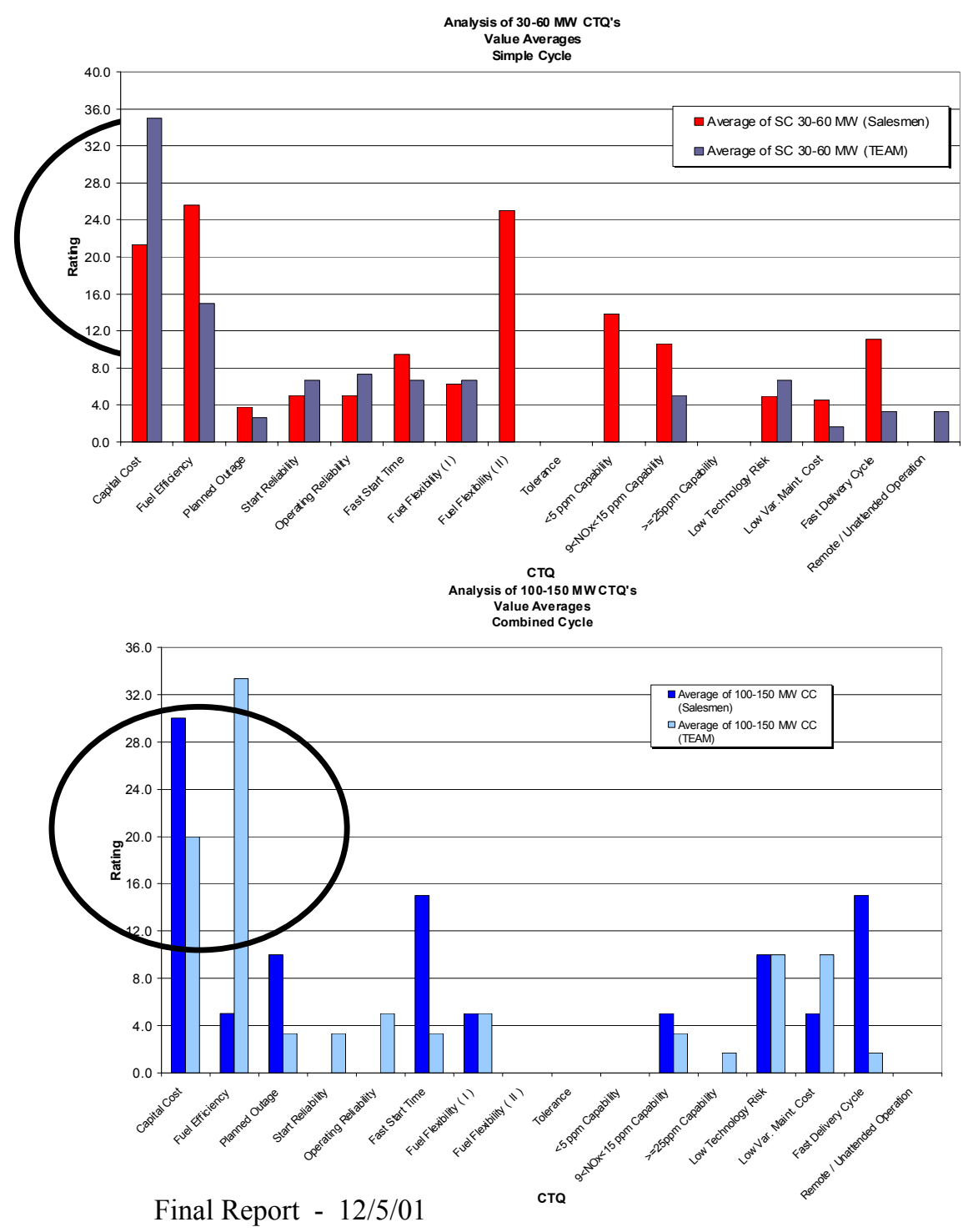


Table 1.2: NGGT Survey - Customer Candidate Profile

$\begin{array}{lccccc} & \text { Utility } & \text { IPP } & \text { EPC } & \text { NUPG } & \text { Total } \\ \text { United States } & 2 & 7 & 3 & 0 & 12 \\ \text { Canada } & 0 & 1 & 0 & 0 & 1 \\ \text { Mexico } & 0 & 0 & 1 & 0 & 1 \\ \text { South America } & 0 & 0 & 0 & 1 & 1 \\ \text { Europe } & 4 & 1 & 2 & 0 & 7 \\ \text { Mid East } & 0 & 0 & 0 & 1 & 1 \\ \text { Asia } & 1 & 0 & 1 & 0 & 2 \\ \text { Total } & 7 & 9 & 7 & 2 & 25\end{array}$


Figure 1.3: Customer Market Survey Results - Producer Types

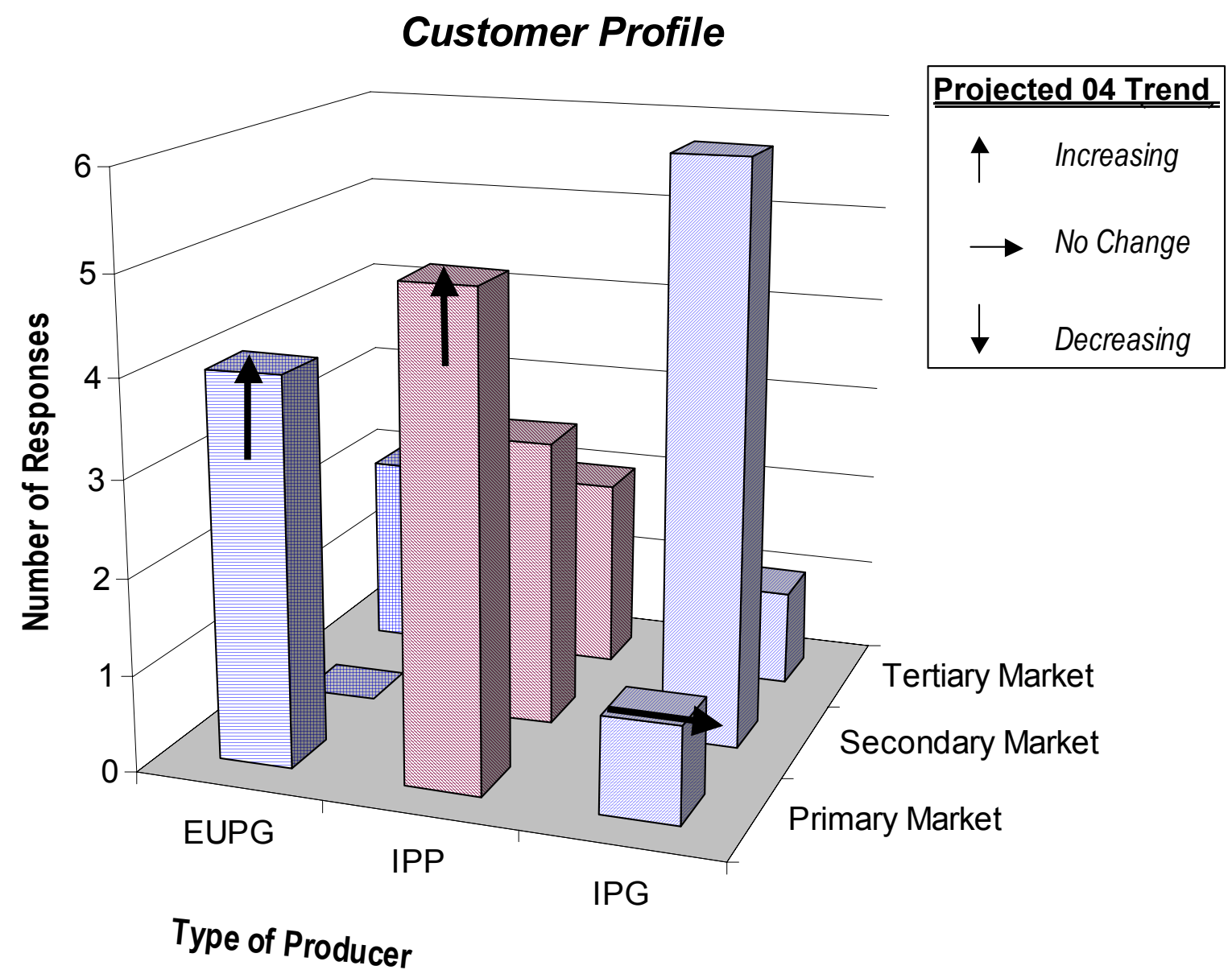


Figure 1.4: NGGT User Profiles
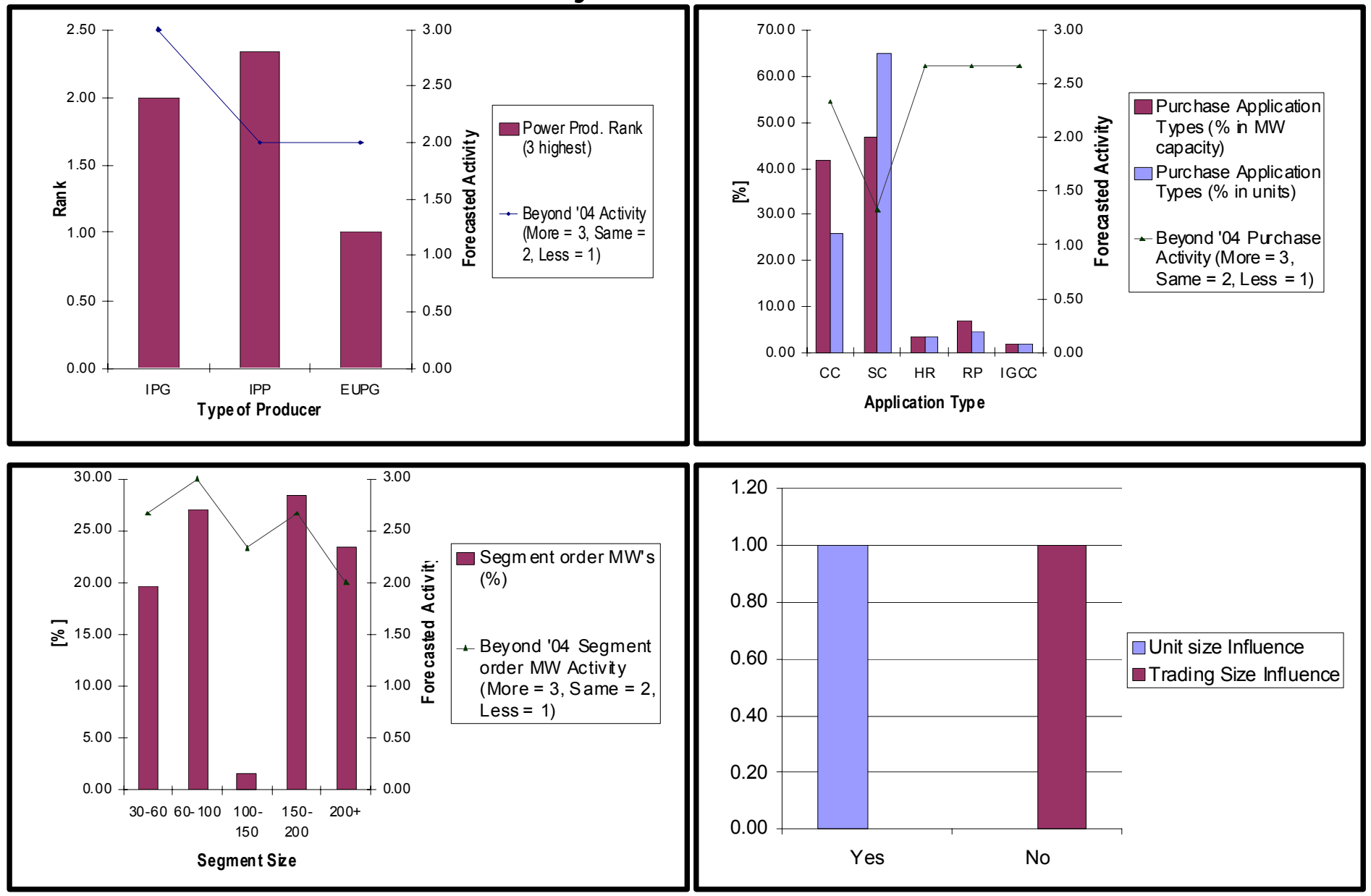


\section{Figure 1.5: NGGT Customer Survey Results - CTQ Rankings}

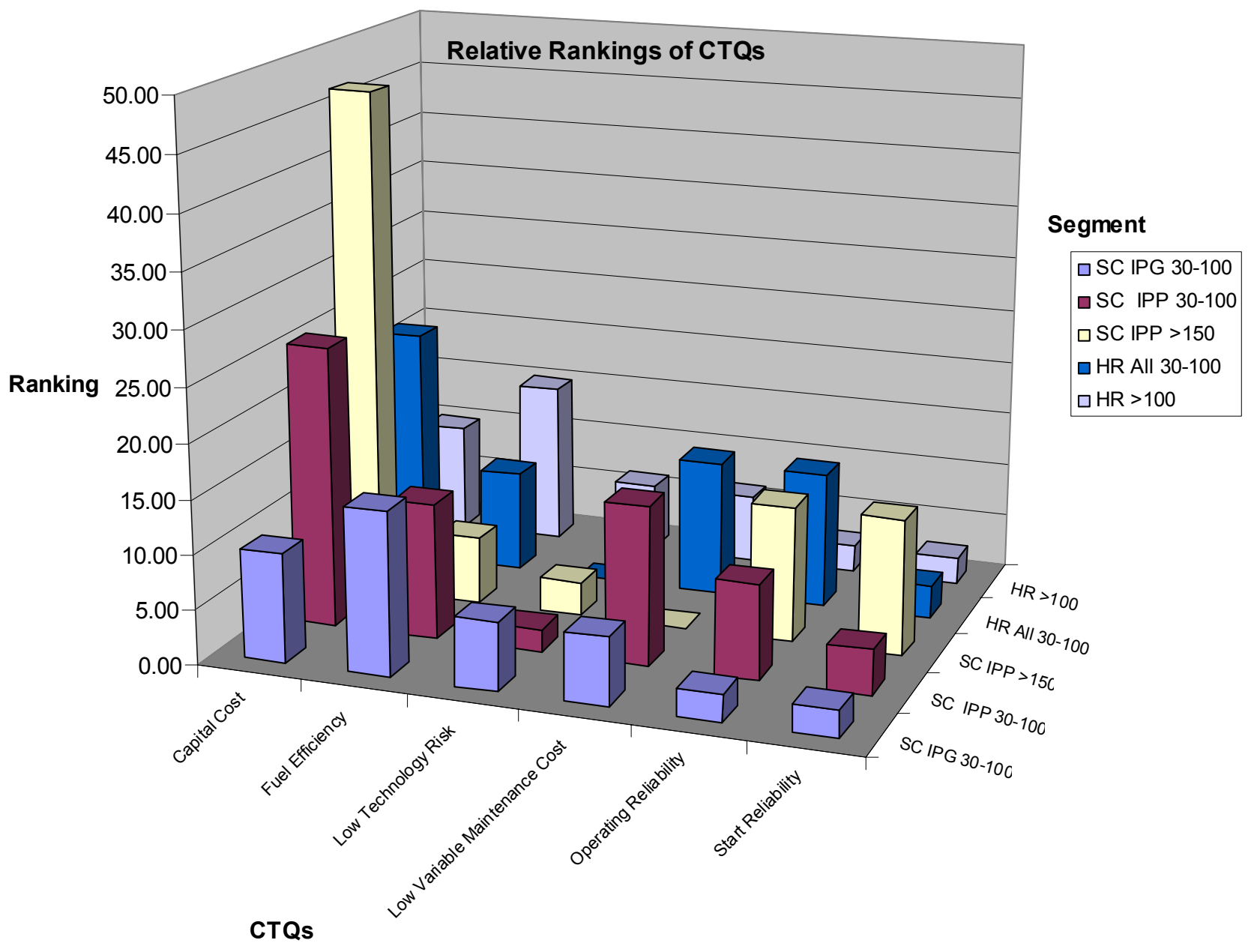




\section{Figure 1.6: NGGT Customer Barriers To Entry}

\section{Preliminary NGGT Customer Barriers To Entry}

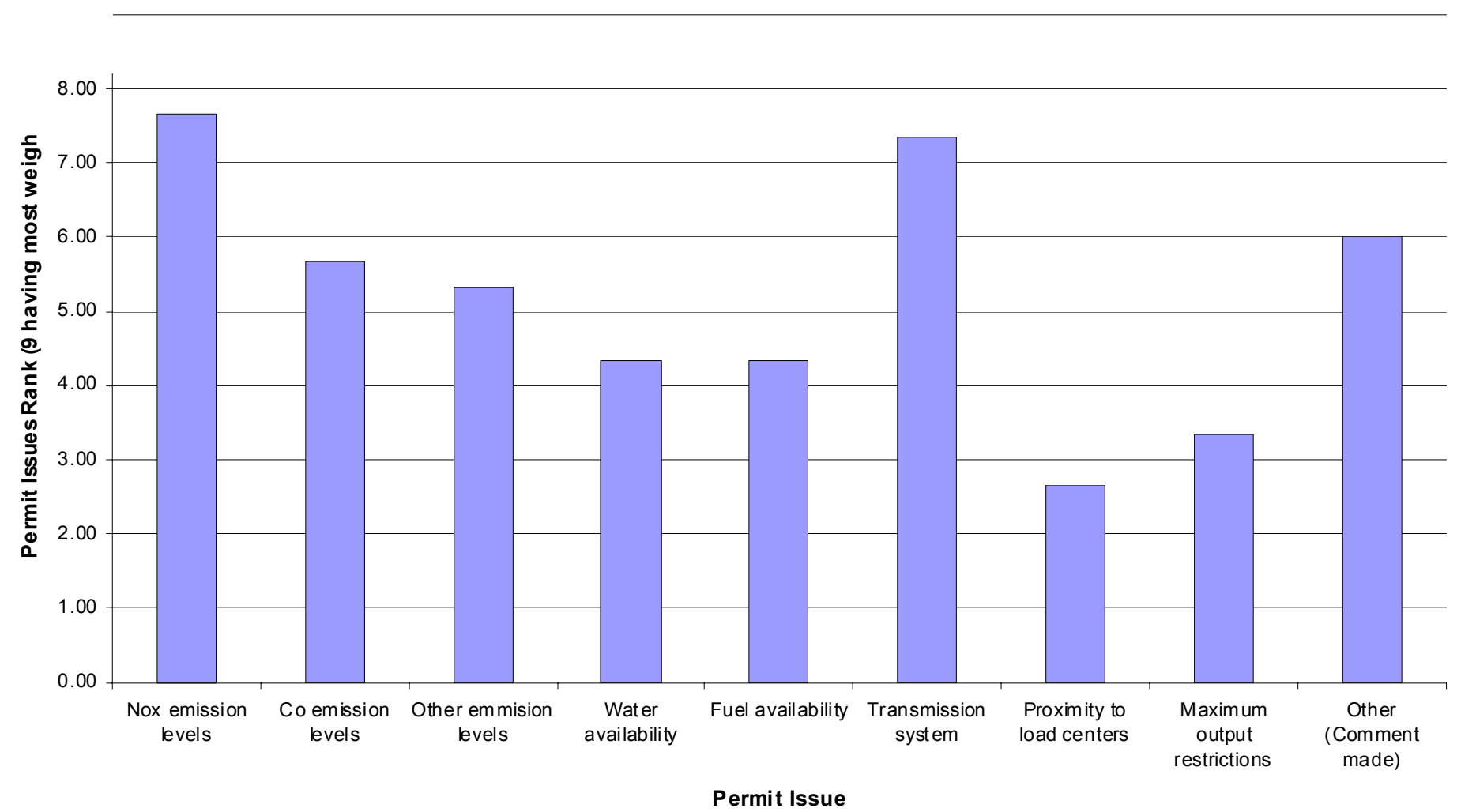




\section{SUMMARY:}

The final Task 1 market analysis recommendation, based on the preliminary results summarized above, concluded that improvements to the US energy situation may be best served in the near/mid term (2002-2009) by a "Technology-Focused" program rather than a specific "Product-Focused" program. Technologies deemed applicable to a NGGT product should be developed anticipating a delayed need (circa 2010). In the interim, many if not all of these technologies could be demonstration tested on various existing products. The Task 1 market analysis results, reviewed with DOE-NETL on 26th January 2001 led to a formal request to DOE-NETL for technical re-direction on 13 March 2001, which was accepted by the DOE on 26 March 2001. Validation of the GEPS market analysis was accomplished initially with a survey of our own extensive GEPS Regional Sales force.

The internal GEPS QFD revealed that initial capital costs (on a dollar per $\mathrm{kW}$ basis) and fuel efficiency are key CTQs for our customers. High reliability, availability and maintainability are perceived to be customer entitlements. Surveys of at least 10 potential customers were conducted using the results from the QFD and confirmed the QFD results. Low variable maintenance costs were found to follow in importance, operating reliability, low NOx capability and low technology risk comprise a third tier of CTQs. Also noted from the customer survey is that there may be a move to more industrial power generation segments with heat recovery systems for cogeneration in the 60 to $100 \mathrm{MW}$ gas turbine size.

As a result of these market analysis results, GEPS re-directed our approach to this study, with DOENETL consensus, in the following manner:

- Task 2 defined the best candidate systems that could achieve the DOE specified performance parameters in the period specified for initial product introduction; circa 2005.

- Task 3 assessed in more detail the candidate systems of Task 2.

- Task 4 identified candidate technologies, both evolutionary and revolutionary, that could be developed and eventually transitioned into the candidate products as growth step improvements.

- Task 5 analyzed how selected configurations/technologies support Vision 21 goals and benefits, and then were viewed from two additional perspectives:

- Assuming the relevant technologies were developed and available for an NGGT market opportunity in 2009/2010, what would be the attributes of the top candidate system.

- Assuming relevant technologies were incorporated into existing new and current field products as they became available, what would be the level of public benefit expectation.

- Task 6 assessed how this could serve multiple users, both in terms of current product incorporations of technology and the candidate systems.

- Task 7 showed potential program costs for development of the candidate systems identified in Task 2, and also how this technology development initiative could be aided by DOE participation. 


\section{Task 2: Options Screening}

Gas turbine configuration options will be developed with a potential for meeting the characteristics identified in the DOE PRDA and the characteristics identified in the market study. These options will be compared with 1999 state of art engines (LM6000 and 6FA) to evaluate potential improvements as required by the DOE PRDA. Service life and part lives will be estimated by comparison with identical or similar parts on existing engines. Reliability, Availability and Maintainability will be estimated based on experience with similar components and prior experience on new product introductions taking into consideration differences in design and design complexity. Preliminary start-up dynamics studies will be performed to estimate start-up times for these concepts.

\section{Task 2.1: Quantifying the Critical to Quality Parameters (CTQ's)}

\section{TASK OBJECTIVE:}

In order to narrow the system choices down to 3 or 4 candidates, the DOE PRDA screening parameters must be quantified as much as possible. The contractor shall perform initial performance and Cost of Electricity (COE) calculations in completing this task. The contractor shall conduct a final brainstorming and concept solidification session, and establish the 1999 state of the art levels of performance. The contractor shall determine targets for net system efficiency, turndown ratio, cost of electricity, service life, emissions levels, operations, maintenance and capital costs, time to start, fuel capabilities and RAM.

\section{INTRODUCTION:}

\section{9-2000 State of the Art Gas Turbine Engines}

The state of the art for aero-derivative engines in the $30-150 \mathrm{MW}$ range in 1999-2000 is exemplified by the LM6000 engine. This engine produces $42.6 \mathrm{MW}$ of power at a nominal efficiency of $41.2 \%$ in simple cycle and produces $56 \mathrm{MW}$ at $52.5 \%$ efficiency in a combined cycle plant. The 2 spool, direct drive LM6000 has accumulated 2.7 million hours in field operation, and has grown $10 \%$ since it was introduced in 1992. The engine utilizes a low-pressure compressor derived from the LM5000/CF6-80C2. The high-pressure compressor is also obtained from the CF680C2 aircraft engine. The PC model uses a single annular combustor while the PD model uses a Dry Low Emissions combustor capable of operating at $25 \mathrm{ppm}$ NOx at full power on natural gas fuel. This combustor operates in the lean premixed mode over its entire operating range. The high pressure and low pressure turbines are both derived from the $\mathrm{CF} 6-80 \mathrm{C} 2$ aircraft engine. The 30 to 1 pressure ratio engine has a nominal firing temperature of $1287.8^{\circ} \mathrm{C}\left(2350^{\circ} \mathrm{F}\right)$. SPRINT and Enhanced SPRINT are two additional developments on the LM6000, which permits the engine to generate between 10 and $40 \%$ additional power by water spray inter-cooling. The LM6000 is used in both base load as well as peaking applications with over 300 starts per year.

The state of the art gas turbine for the heavy duty engine in the $30-150 \mathrm{MW}$ range is the GE MS6001FA gas turbine, commonly known as the 6FA, which is the mid-size model of GEPS's family of F-class, heavy duty gas turbines. The first 6FA gas turbine was introduced in 1993, and the first unit entered commercial service in 1996. The 6FA produces $70.1 \mathrm{MW}$ of simple cycle power at 
a thermal efficiency of $34.2 \%$, and $107.1 \mathrm{MW}$ of combined cycle power at $53 \%$ efficiency and a compressor pressure ratio of 14.9 to 1 . GE's F-class gas turbines are the world's largest, most experienced fleet of advanced technology heavy duty gas turbines with over 4.2 million combined operating hours. The 6FA is already used in a variety of applications including simple cycle, combined cycle, integrated gasification combined cycle, single and multi-shaft applications, base load power generation, cogeneration, and district heating. The 6FA also utilize GE's leading technology Dry Low NOx (DLN) combustion system. The DLN-2 can achieve NOx emissions levels of 25 ppm or less and CO emission of 15 ppm or less. As with other F technology units, the 6FA can burn a wide variety of fuels in addition to natural gas, including gasified coal, distillate, and others. The following Table 2.1.1 summarizes the LM6000 and 6FA performance parameters.

Table 2.1.1 1999-2000 State of the Art Engines

\begin{tabular}{|c|c|c|}
\hline Characteristic & LM6000 & 6FA \\
\hline Output Power & $42.6 \mathrm{MW}$ & $70.1 \mathrm{MW}$ \\
\hline Thermal Efficiency (shaft) & $41.2 \%(\mathrm{LHV})$ & $34.2 \%(\mathrm{LHV})$ \\
\hline NOx Emissions & $25 \mathrm{ppm}$ & $25 \mathrm{ppm}$ \\
\hline Turn-down & Down to $75 \%$ power & Down to $50 \%$ power \\
\hline Capable of 'fast start' & Yes & No \\
\hline Capable of $>400$ starts/year & Yes & Yes \\
\hline $\begin{array}{l}\text { Cost of Gen Set (simple } \\
\text { cycle)* }\end{array}$ & \$ 346/KW & $\$ 314 / \mathrm{KW}$ \\
\hline $\begin{array}{l}\text { Cost of Electricity for a } \\
\text { Simple Cycle plant, running } \\
2000 \mathrm{hrs} / \text { year at } \\
\$ 3.5 / \mathrm{MMBTU} H \mathrm{HV}\end{array}$ & --Confidential-- & --Confidential-- \\
\hline Fuel Flexibility & Natural gas and distillate & $\begin{array}{l}\text { Natural gas, distillate, } \\
\text { gasified coal, others }\end{array}$ \\
\hline Multiple Applications & $\begin{array}{l}\text { Simple cycle power plant, } \\
\text { and combined cycle base } \\
\text { load and peaking power } \\
\text { plants including } \\
\text { cogeneration and district } \\
\text { heating }\end{array}$ & $\begin{array}{l}\text { Simple cycle, combined } \\
\text { cycle and integrated } \\
\text { gasification combined } \\
\text { cycle, base load power } \\
\text { generation, cogeneration } \\
\text { and district heating }\end{array}$ \\
\hline
\end{tabular}

* GTW 2000 prices have been used as these are commonly known 


\section{RESULTS AND DISCUSSION:}

\section{Performance Targets for Synthesis of Design Options}

Performance targets for the synthesis of new designs were based on:

1) Performance of the current products in the market place, i.e. the LM6000 and the 6FA

2) Results of the market survey of customers that showed a need to reduce cost of electricity by $15 \%$ to obtain significant public benefits (see Task 5.2 responses).

These targets are very much in line with the PRDA targets.

Table 2.1.2: Near/Mid Term Design Targets for the Next Generation Gas Turbine Engine

\begin{tabular}{|c|c|c|}
\hline Parameter & Aero-Derivative Engine Target & Heavy Duty Engine Target \\
\hline Net Plant Efficiency & $46 \%$ & $39 \%$ \\
\hline Turn-down ratio & $50 \%$ & $50 \%$ \\
\hline Cost of Electricity & $15 \%$ lower than LM6000 & $15 \%$ lower than $6 \mathrm{FA}$ \\
\hline Service Life & Same as LM6000 & Same as 6FA \\
\hline $\begin{array}{l}\text { Operations \& } \\
\text { Maintenance Costs }\end{array}$ & $15 \%$ lower than LM6000 & $15 \%$ lower than $6 \mathrm{FA}$ \\
\hline $\begin{array}{l}\text { Capability to start }>400 \\
\text { times per year }\end{array}$ & $\begin{array}{l}\text { Yes, without affecting service } \\
\text { life }\end{array}$ & Yes, without affecting service life \\
\hline Time to start & $<10$ minutes & $<10$ minutes \\
\hline Emissions & 25PPM, <5ppm with SCR & 25PPM, <5ppm with SCR \\
\hline Fuel Capabilities & $\begin{array}{l}\text { Natural Gas and Distillate fuel } \\
\text { (back up) }\end{array}$ & $\begin{array}{l}\text { Natural Gas and Distillate fuel } \\
\text { (back up) }\end{array}$ \\
\hline RAM & Improved above LM6000 & Improved above 6FA \\
\hline
\end{tabular}

\section{Concept Development}

\section{$\underline{\text { Aero-derivative Options }}$}

The approach taken by the team to improve the efficiency for the aeroderivative gas turbine engines utilizes an intercooler between the low-pressure compressor and the high-pressure compressor.

\section{$\underline{\text { LM6000 and GE90 }}$}

Both the LM6000 and the GE90 are 2 shaft gas turbine engines. In the LM6000, the low-pressure compressor is driven by the low-pressure turbine, which also drives the load i.e., the generator. The high-pressure compressor is driven by the high-pressure turbine. Thermodynamic analyses of Brayton cycle engines has shown that the efficiency of the gas turbine can be increased substantially by placing an intercooler between the low-pressure and the high-pressure compressors. This intercooler effectively reduces the work done in the high-pressure compressor to get to the same pressure ratio. The LM6000 runs to a compressor discharge temperature limit which is set by material properties. By inter-cooling the air entering the compressor, the temperature of the air exiting the high-pressure compressor also drops well below this limit, and permits the compressor to run to a higher pressure ratio. The cooler air temperature is also advantageous in cooling hot section components, permitting the increase in the firing temperature of the gas turbine engine while 
maintaining component temperatures at acceptable levels. Overall, an increase in the pressure ratio across the turbine results in greater extraction of energy in the turbine, with a resultant increase in gas turbine efficiency.

\section{Aero- derivative NGGT Concepts}

Several concepts were generated for the aero-derivative engines. Key features that were varied include the core component lineage, and design conditions for each of the hardware combinations. Select concepts are described in detail below. A close-coupled free power turbine design was selected for all concepts as this permits the engine to work with both 50 and $60 \mathrm{HZ}$ generators without the need for a gearbox. This also allows the engine to compete in both the U.S. $60 \mathrm{~Hz}$ markets and the European and Asian $50 \mathrm{~Hz}$ markets. Inter-cooling concepts considered for the Next Generation Gas Turbine configurations studied. These included: a dry inter-cooled cycle with a free power turbine; a wet inter-cooled concept obtained by evaporation of water in the compressed air stream; and a downstream heat recovery steam generator to produce steam to be injected in the combustor for power and efficiency augmentation.

\section{LM6000 Based Inter-cooled Machine}

\section{Low-pressure Compressor}

With inter-cooling the high pressure compressor inlet temperature is reduced. In order to match the corrected flow characteristics for which the existing LM6000 HP compressor is designed, the highpressure compressor mass flow has to be increased. This increase in mass flow for the high-pressure compressor has to be accompanied by a corresponding increase in the mass flow of the low-pressure compressor. The approach adopted by the team for the LM6000 based concept adds a zeroth stage to the existing compressor. This increases the mass flow through the compressor between $10-15 \%$. In addition, the speed of the low-pressure compressor is increased from $3600 \mathrm{rpm}$ to $3930 \mathrm{rpm}$. The low-pressure compressor for the LM6000 is based on the LM5000 low-pressure compressor. The combination of increased low-pressure compressor speed and the addition of a stage in the inlet of the compressor is expected to result in $34 \%$ increase in mass flow.

Intercooler

A high efficiency intercooler with a $5 \%$ pressure drop is utilized in the design. The air temperature at the exit of the intercooler is assumed to be $32.2^{\circ} \mathrm{C}\left(90^{\circ} \mathrm{F}\right)$ for this concept. Intercooler designs could utilize water-cooled or fin-farm array as cooling medium.

\section{High-pressure Compressor/Combustor/Turbine}

The high-pressure compressor is unchanged from the LM6000. The design uses the Existing Dry Low Emissions Combustor for the performance calculations, with the emissions characteristics of the combustion system of Ultra-low NOx emissions to be obtained with a technology development program. The High-pressure turbine is unchanged from the LM6000 design except for a rotation of the first stage vane that permits the increase in its firing temperature. Improvements in turbine cooling design are needed to reduce thermal stresses due to an increase in the difference between the firing temperature and coolant temperature. 


\section{$\underline{\text { Low-Pressure Compressor/Intermediate-Pressure Turbine }}$}

The low-pressure compressor is driven by an intermediate pressure turbine. The turbine design selected for this concept utilizes a 2-stage turbine for maximum efficiency.

Free Power Turbine

A six-stage power turbine design was selected for this concept, again with a view of maximizing efficiency. The design follows the guidelines developed for the LM6000 turbine. This turbine drives the load i.e., the electrical generator alone and is not connected to the low-pressure compressor (unlike the LM6000). The advantage of this arrangement is that the air-flow in the machine can be modulated downwards with reducing load by allowing the low pressure compressor speed to drop as the load decreases. This allows the engine to operate at higher efficiency over a wider load setting. This turbine is supported by its own bearings.

All concepts also utilize an auxiliary circuit to heat the natural gas fuel using exhaust heat.

Other concepts developed and considered used wet inter-cooling of the low-pressure compressor discharge air. Cooling in this concept is obtained by evaporating water into the air stream. Such a concept would have an advantage of a simpler intercooler design, but could require increased quantities of de-ionized water. Steam injection into the combustor for power and augmentation was also considered. This concept requires a heat recovery steam generator in the exhaust stack, and a supply of de-ionized water.

\section{GE90 Based Aero Concept.}

The GE90 engine is the latest and the most sophisticated aircraft engine developed by GE Aircraft Engines. This engine also has the potential for an advanced aero-derivative industrial gas turbine engine. An aero-derivative engine using the GE90 as the core engine would be very similar to the one based on the LM6000 described above with some changes. The cycle is the same i.e., a low pressure compressor is used to compress the incoming air flow, an intercooler cools this air before entry to the high pressure compressor, and a Dry Low Emissions combustor is used to increase the temperature of the air before it expands through the high pressure turbine, the intermediate pressure turbine and the free power turbines. Changes would include a new Low Pressure compressor, a new intermediate pressure turbine to drive the LP compressor, an a redesigned combustor for dry low emissions capability.

Table 2.1.3 Key features of the aero derivative concepts:

\begin{tabular}{|l|}
\hline Fast start capability of the turbo-machinery $(<10 \mathrm{~min}$ to full power $)$ \\
\hline Designed for high cyclic life (permits $>400$ starts/yr) \\
\hline High simple cycle efficiency $(44-47 \%)$ \\
\hline
\end{tabular}




\section{Hybrid Options}

Hybrid concepts developed here bring to the customer in one package the design advantages of heavy duty reliability and ruggedness in the low pressure compressor with the sophistication and efficiency of aircraft engines in the aero core engine.

One of the key features of an aero-derivative gas turbine engine is the ability to replace the engine in the package with another engine within a short period $(<1$ week). The removed gas turbine engine can then be taken to a depot for overhaul. This feature allows the aero-derivative-packaged-power plant to minimize the duration of outages required for engine overhaul. This feature of the aeroderivatives is retained by the use of a removable core aero-derivative engine, while utilizing heavy duty design for the LP compressor that brings the durability of heavy duty engines to the package.

\section{LM6000 based Hybrid Engine}

This concept may be described as being similar to the LM6000 based aero option, with the lowpressure compressor replaced by one developed by using the first 5 stages of 6FA gas turbine engine. The 6FA operating speed is about $5200 \mathrm{rpm}$. The airflow capacity is higher than the aero low pressure compressor based on the LM6000. The higher airflow also results in a higher engine pressure ratio. The intermediate pressure turbine is a single-stage turbine. This is possible as the speed of the stage is increased from $3930 \mathrm{rpm}$ to $5200 \mathrm{rpm}$ at design-point. The power turbine, as in the previous concepts, is a free power turbine driving the generator.

\section{GE90 based Hybrid Engine}

This option has the same basic description as the GE90 based aero option above with the lowpressure compressor replaced by one developed by using the first 4 stages of 6FA gas turbine engine.

Performance parameters for all aero, hybrid and heavy duty concepts are summarized in Table 2.1.4

\section{Heavy Duty Options}

\section{2-Shaft Concept}

Several Heavy-duty heavy duty concepts were investigated, all based on a common, 2-shaft arrangement. The 2-shaft arrangement consists of a synchronous shaft rotating at 3600 RPM, in conjunction with a non-synchronous shaft rotating at a higher rotational speed. The salient advantage of the high rotational speed of the asynchronous shaft is that it enables higher power density turbomachinery, and hence lower cost.

The cold-end of the synchronous shaft drives the generator, which also provides starting means to the high-speed shaft. Flow passes from the LPC to the high-pressure compressor (HPC), where it is boosted in pressure. The overall cycle pressure ratio is thus about 40:1. The pressure ratio of the first stage turbine is set low enough that the second stage is an uncooled design, reducing design complexity, and cost. Flow from the HPC is passed on to a heat exchanger situated between the HPC 
and the LPC. The heat exchanger is used to pre-heat the fuel stream prior to its delivery at the combustor, utilizing what would otherwise be wasted heat.

Three firing temperature classes were considered in conjunction with the 2-shaft design: E-class, Fclass, and FB or G-class. The E-class approach has the advantage of the lowest emissions, high reliability, and low cooling flow requirements. At the other end of the firing temperature spectrum, the G-class provides the highest performance, at the expense of more severe cooling flow requirements and worse emissions performance. Intercooling was considered for this cycle. However, since the temperature of the air exiting the LPC is low, the added performance of an intercooled cycle does not offset the added complexity and cost.

Performance of the aero, hybrid and heavy duty concept is summarized in Table 2.1.4.

Table 2.1.4: Table of Key Design Parameters for Concept Considered for the NGGT Engine

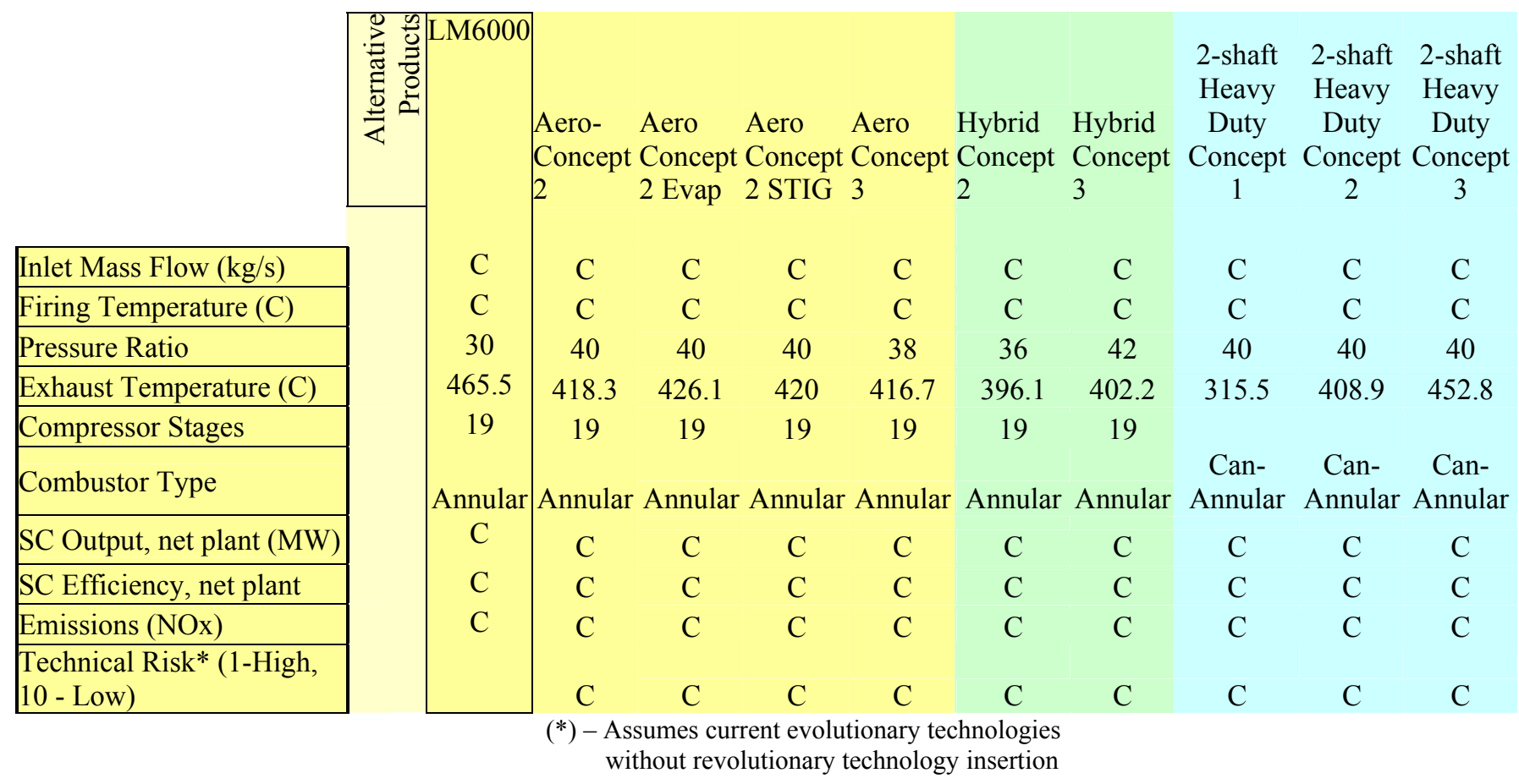

Note: (C) denotes GE Confidential Information 


\section{SUMMARY:}

Concepts have been developed in this task that have a high potential of meeting product CTQs as defined by the customer survey conducted in task 1 .

Inter-cooling has been considered for aero-derivative gas turbine engines as a prime concept to lower the temperature of the cooling air and reduce turbomachinery costs $(\$ / K W)$. Two and three spool concepts permit modulation of air-flow by allowing the low pressure compressor speed to drop as the load is dropped. This flexibility enhances the ability of the machine to retain fuel-efficiencies, while operating at part power. Significant advances in combustion technology are needed to meet 15 PPM NOx requirements, as the operating conditions of these inter-cooled machines are outside manufacturers' experience band.

A 2-shaft concept with technology advancements in the sealing, compressor aero, combustion and materials has been selected for heavy duty machines. 


\section{Task 2.2: Complete the QFD Matrix}

\section{TASK OBJECTIVE:}

The contractor shall use Quality Function Deployment (QFD) to match up the various system options with the noted CTQ's. This method allows quantitative ranking of the various systems, which leads to the selection of three or four candidates to continue on to more detailed analysis and study.

\section{INTRODUCTION:}

In order to select a concept that best meets customer requirements a Quality Function Deployment process has been used. This process has 3 essential steps. A table of product attributes based on requirements developed in Task 1 for the concepts to be evaluated as shown in Table 2.2.1. For each requirement, the best-rated concept is scored with the highest score of 10 , while the least rated concept is scored a one. Scores of the remaining concepts are determined by a depth-in-range technique. Next a table of weights ranking each of the requirements for each market segment is developed from the customer survey results conducted in Task 1 as shown in Table 2.2.2. This table provides relative importance of each of the requirements in the decision making process used by the customers in each of the market segments. To develop a ranking score of products for each market segment, the weight of each CTQ for a market segment is multiplied by the depth-in-range ranking of the product concept and summed across the product CTQs. Table 2.2.2 shows the summed product for the simple cycle market the NGGT is designed to serve. The concept with the highest score in each market segment best fits the needs of the segment.

\section{RESULTS AND DISCUSSION:}

\section{Quality Function Deployment (QFD) Matrix}

The 3 Dimensional Quality Function Deployment technique requires clear definition of the CTQs. The set of CTQs used for the QFD were initially based on the characteristics published in the PRDA. These were then refined with inputs of a cross-functional team. These CTQs were subsequently used to survey the GE Global Sales Team. The results of the Sales Team survey validated the CTQs, and the relative rankings of the top several CTQs, namely: first cost, capital cost (in $\$ / \mathrm{KW}$ installed), and net plant fuel efficiency. Another survey was conducted with a select set of key GE customers. Inputs from these validated the relative rankings of the CTQ's in the market segment NGGT is expected to serve.

Product attributes such as first cost, fuel efficiency, start characteristics, and reliability were employed to evaluate several concepts in each of the 3 segments: aero, hybrid, and heavy duty. These were ranked using the depth-in-range technique, with the best getting a 10 and the worst design getting a score of 1 . Product rankings were then developed by multiplying the attribute rank by the CTQ rank, and then summing over all attributes and CTQs. Results show that the hybrid concept that utilizes a low-pressure compressor based on heavy duty design and using a core engine based on the LM6000 with increased Firing temperature scored highest. This is due to a combination of high efficiency and lower cost made possible by using best features of the heavy duty and aero technologies. Scores of the top concepts are shown in Table 2.2.2. 
Table 2.2.1 Table of NGGT Concept Attributes

\begin{tabular}{|l|}
\multicolumn{1}{|c|}{ Customer Requirements } \\
Capital Cost (all in owners) \\
\hline Fuel Efficiency (Plant basis) \\
Planned Outage Rate (availability) \\
Starting Reliability \\
\hline Operating Reliability \\
Fast Start Time (less than 10 minutes) \\
Fuel Flexibility: NG, Distillate \\
Fuel Flexibility: Refinery, Biomass, Syn Gas. \\
\hline Tolerance for Fuel Contaminants \\
\hline NOx Emissions Capability: $<5$ PPM \\
\hline NOx Emissions Capability: 9 - 15 PPM \\
\hline NOx Emissions Capability: $\leq 25$ PPM \\
\hline Low Technology Risk \\
Low Variable Maintenance Cost \\
Fast Delivery Cycle (Order to Commercial Operation) \\
Remote / Unattended Operation \\
Minimum load to maintain NOx emissions
\end{tabular}

Note: (C) denotes GE Confidential Information

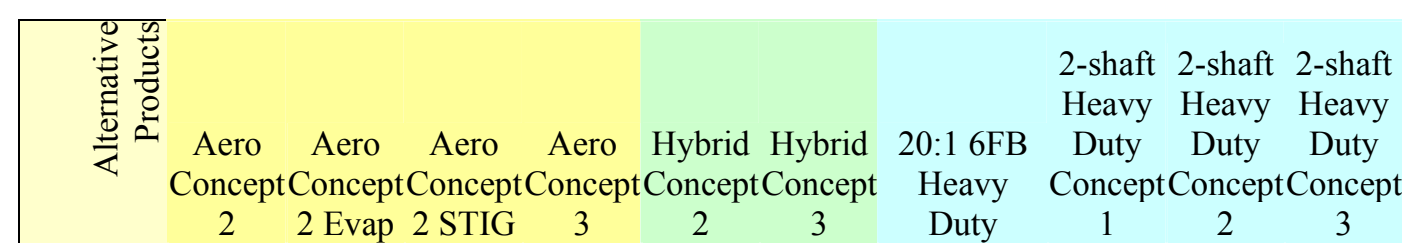

\begin{tabular}{|c|c|c|c|c|c|c|c|c|c|c|}
\hline$\$ / K W$ & $\mathrm{C}$ & $\mathrm{C}$ & $\mathrm{C}$ & $\mathrm{C}$ & $\mathrm{C}$ & $\mathrm{C}$ & $\mathrm{C}$ & $\mathrm{C}$ & $\mathrm{C}$ & $\mathrm{C}$ \\
\hline$\%$ & $\mathrm{C}$ & $\mathrm{C}$ & $\mathrm{C}$ & $\mathrm{C}$ & $\mathrm{C}$ & $\mathrm{C}$ & $\mathrm{C}$ & $\mathrm{C}$ & $\mathrm{C}$ & $\mathrm{C}$ \\
\hline$\%$ & $\mathrm{C}$ & $\mathrm{C}$ & $\mathrm{C}$ & $\mathrm{C}$ & $\mathrm{C}$ & $\mathrm{C}$ & $\mathrm{C}$ & $\mathrm{C}$ & $\mathrm{C}$ & $\mathrm{C}$ \\
\hline$\%$ & $\mathrm{C}$ & $\mathrm{C}$ & $\mathrm{C}$ & $\mathrm{C}$ & $\mathrm{C}$ & $\mathrm{C}$ & $\mathrm{C}$ & $\mathrm{C}$ & $\mathrm{C}$ & $\mathrm{C}$ \\
\hline$\%$ & $\mathrm{C}$ & $\mathrm{C}$ & $\mathrm{C}$ & $\mathrm{C}$ & & $\mathrm{C}$ & $\mathrm{C}$ & $\mathrm{C}$ & $\mathrm{C}$ & $\mathrm{C}$ \\
\hline \multirow[t]{4}{*}{ minutes } & 9 & 10 & 40 & 10 & 9 & 9 & 30 & 30 & 30 & 30 \\
\hline & yes & yes & yes & yes & yes & yes & yes & yes & yes & yes \\
\hline & no & no & no & no & no & no & no & no & no & no \\
\hline & no & no & no & no & no & no & no & no & no & no \\
\hline ppm & no & no & no & no & no & no & no & no & no & no \\
\hline ppm & 15 & 15 & 15 & 15 & 15 & 15 & 9 ppm blk 2 & 9 & 9 & 9 \\
\hline ppm & 15 & 15 & 15 & 15 & 15 & 15 & 25 blk 1 & 15 & 15 & 15 \\
\hline qualitative & $\mathrm{C}$ & $\mathrm{C}$ & $\mathrm{C}$ & $\mathrm{C}$ & $\mathrm{C}$ & $\mathrm{C}$ & $\mathrm{C}$ & $\mathrm{C}$ & $\mathrm{C}$ & $\mathrm{C}$ \\
\hline $\mathrm{C} / \mathrm{KWH}$ & $\mathrm{C}$ & $\mathrm{C}$ & $\mathrm{C}$ & $\mathrm{C}$ & $\mathrm{C}$ & $\mathrm{C}$ & $\mathrm{C}$ & $\mathrm{C}$ & $\mathrm{C}$ & $\mathrm{C}$ \\
\hline \multirow[t]{2}{*}{ months } & $\mathrm{C}$ & $\mathrm{C}$ & $\mathrm{C}$ & $\mathrm{C}$ & $\mathrm{C}$ & $\mathrm{C}$ & $\mathrm{C}$ & $\mathrm{C}$ & $\mathrm{C}$ & $\mathrm{C}$ \\
\hline & yes & yes & yes & yes & yes & yes & yes & yes & yes & yes \\
\hline$\%$ & $\mathrm{C}$ & $\mathrm{C}$ & $\mathrm{C}$ & $\mathrm{C}$ & $\mathrm{C}$ & $\mathrm{C}$ & $\mathrm{C}$ & $\mathrm{C}$ & $\mathrm{C}$ & $\mathrm{C}$ \\
\hline
\end{tabular}


Table 2.2.2: Results of the 3D-QFD showing scores of each of the candidate designs for Simple Cycle Applications.

\begin{tabular}{|l|c|}
\hline Alternative & $\begin{array}{l}\text { Market Volume } \\
\text { Weighted Aggregate }\end{array}$ \\
\hline Hybrid Concept 3 & 267 \\
\hline Aero Concept 3 & 243 \\
\hline Aero Concept 2 Evap & 241 \\
\hline Aero Concept 2 & 233 \\
\hline Hybrid Concept 2 & 231 \\
\hline 20:1 6FB+E Heavy Duty & 214 \\
\hline Aero Concept 2 STIG & 207 \\
\hline 2-Shaft Heavy Duty Concept 3 & 201 \\
\hline 2-Shaft Heavy Duty Concept 2 & 196 \\
\hline LM9000 Concept with LM6 & 188 \\
\hline 2-Shaft Heavy Duty Concept 1 & 183 \\
\hline LM9000 Concept with GE90 & 168 \\
\hline
\end{tabular}

\section{Description of the Best Aero and Hybrid Concepts}

Of the Several aero concepts evaluated in the 3D-QFD, concept \#3 scored highest, mainly due to the higher net plant efficiency, as well lower specific cost $(\$ / K W)$. (See in table 2.2.1). The higher efficiency is obtained by increasing the firing temperature with the use of improved cooling technology in the high-pressure turbine. Increased firing temperature also results in a power increase with modest increase in cost of the hardware, which in the end results in a lower specific cost. The higher firing temperature of Concept 3 will require development of Low NOx Combustion technology beyond the current state of the art.

The highest rated hybrid concept is Hybrid Concept 3 that also utilized an increased firing temperature. This assumes improvements in turbine cooling technology as well as a new Dry Low Emissions Combustor design. This concept scored the highest of all concepts as it combines a low cost booster derived from a heavy duty engine, with the high technology core engine based on the LM6000. The higher power output of this concept with marginal increase in costs, results in a reduction in net plant specific cost $(\$ / \mathrm{KW})$.

Although not in the 3D-QFD criteria, the free power turbine chosen for these concepts will permit them to service both the 60 and the $50 \mathrm{~Hz}$ markets without a gearbox.

\section{Description of the Best Heavy duty Concept}

The best heavy duty concept utilizes a "G" firing temperature to get high simple cycle efficiency. This higher firing temperature requires significant cooling design advances in the high temperature turbomachinery. Higher component efficiencies are obtained by the use technology developments 
reducing leakage and seal flows, and improved aerodynamics in the compressors and turbines. Higher temperature alloys (aircraft) are utilized in the mid section of the high-pressure spool.

Significant advances are also anticipated in the area of combustion. High firing temperatures, coupled with an overall pressure ratio of 40:1, are beyond current heavy duty design experience and will need additional development effort. Like the aeroderivative LM6000 engine, the output in the 2 shaft heavy duty engine can be modulated by permitting the high-speed spool rotational speed to drop as the load is reduced. The 2 shaft design also permits the low pressure synchronous spool to operate (at somewhat different ratings) at 3000 , rpm serving the $50 \mathrm{~Hz}$ market without the need of a gearbox.

\section{SUMMARY:}

A 3D Quality Function Deployment technique has been used to select candidate aero, hybrid and heavy duty engine concepts for the Next Generation Gas Turbine. The Critical to Quality (CTQ) parameters for the selection process have been validated with surveys of the GE Global Sales Team, as well as with a select group of key GE customers. Several concepts were generated and concept or product attributes such as efficiency, start capability, first cost etc were assessed on a preliminary basis. These assessments were then ranked and scored for each of the market segments the NGGT machine is expected to serve. Table 2.2.3 lists the highest ranked concepts in each of the aero, the hybrid and the heavy duty categories.

Based on the scores developed in the 3D QFD, three concepts were selected for further study.

Table 2.2.3: Downselected Aero, Hybrid and Heavy duty Concepts for the NGGT Program

\begin{tabular}{|l|l|l|l|}
\hline Machine Type & Aero-derivative & Hybrid & Heavy Duty \\
\hline Selected Concept & Aero Concept 3 & Hybrid Concept 3 & 2 shaft Concept 3 \\
\hline
\end{tabular}




\section{Task 3: Detailed Analysis of Candidate Systems}

From the candidate systems selected as a deliverable of Task 2, the contractor shall perform detailed analyses to determine the optimum systems. The contractor shall recommend the best system based on an aero-derivative core and the best system based on a heavy duty core, and make an effort to recommend best hybrid cycles also.

\section{Task 3.1: Performance Calculations}

\section{TASK OBJECTIVE:}

The contractor shall conduct performance feasibility studies on the candidate systems to determine their performance including efficiency, turndown ratios, time to start, and emissions. The contractor shall present the results of this task in a table with the above-mentioned information for the three or four candidate systems for use in Task 3.3.

\section{INTRODUCTION:}

Preliminary Design (PD) tools (proprietary to GE) were used to synthesize preliminary designs of the selected concepts. Design includes setting the number of compression/turbine stages determining combustor design requirements, setting cooling flow needs for the hot section components, and lastly, evaluating performance characteristics for each of the sub-components. Preliminary evaluation of the designs also included comparisons of key component parameters with current experience bands. All performance was estimated at $15^{\circ} \mathrm{C}\left(59^{\circ} \mathrm{F}\right) / 60 \%$ Relative Humidity with nominal inlet /exhaust losses. Generator efficiency, as well as natural gas compression auxiliary loads, was also included in the cycle calculations. Methane fuel was assumed in all cases.

\section{RESULTS AND DISCUSSION:}

Table 3.1.1: Performance characteristics of the downselected candidates

\begin{tabular}{|l|c|c|c|}
\hline Concept & Aero-Derivative & Hybrid & Heavy duty \\
\hline Selected Candidate & Aero Concept 3 & Hybrid Concept3 & 2 Shaft Concept 3 \\
\hline Characteristics: & & & C \\
\hline SC Efficiency, \% net plant & C & C & C \\
\hline Net plant Output, MW & C & C & C \\
\hline Turn-down, \% of baseload & C & 10 & 30. \\
\hline Time to start, min. & 10 & 15 & 15 \\
\hline $\begin{array}{l}\text { NOx Emissions, ppmv } \\
@ 15 \% \text { O2 }\end{array}$ & 15 & Yes & Yes \\
\hline $\begin{array}{l}\text { Capability for }>400 \\
\text { starts/year }\end{array}$ & Yes & & \\
\hline
\end{tabular}

Note: (C) denotes GE Confidential Information 


\section{Heavy Duty Concept}

\section{$\underline{\text { NGGT Heavy Duty Machine Performance Calculations }}$}

Performance estimates for the heavy duty machines were made using a Gate Cycle model. This tool was used to establish design point thermodynamic cycle conditions for E-class, F-class, and G-class firing temperature concepts. Technology enhancements for each class were converted to program input parameters such as component efficiency, system pressure loss, cooling flow, etc., to establish overall system performance.

Assumptions used for the E-class concept are in line with current technology for this level of firing temperature. Hot gas path temperatures are established to parallel the capability of current materials. F-class and G-class products include enabling technologies that will be introduced in the next 2 years.

\section{Combustor Performance}

Preliminary design calculations show that the firing temperatures would need to increase above E class levels. Though these temperatures are not out of the experience base for the heavy duty engines ( $\mathrm{G}$ and $\mathrm{H}$ class technologies) these temperatures would be reached with significantly higher operating pressures $(\mathrm{OPR}>40)$. In addition, the flame temperatures required for these turbine firing temperatures are also significantly higher, leading to a need for new technology development in order to reach 15 PPM NOx emissions. Performance calculations have assumed that this enabling technology would be available for implementation into the selected concepts.

\section{SUMMARY:}

Preliminary analyses of the selected aeroderivative and hybrid aero/heavy duty Candidate Designs show that these have the performance and operating characteristics that meet program objectives with minimal evolutionary and no revolutionary technology development, except to possibly meet emissions requirements. The 2-shaft heavy duty heavy duty candidate is the one that would be able to incorporate all of the identified technologies from Task 4. 


\section{Task 3.2: Reliability, Availability, and Maintainability Assessment}

\section{TASK OBJECTIVE:}

The contractor shall assess the service life as well as the RAM characteristics of the candidate systems based on field experience of similar existing gas turbine products, and use the results of this Sub-Task in Task 3.3.

\section{INTRODUCTION:}

The objective of this reliability analysis is to combine demonstrated power plant Operational, Reliability and Maintenance (RAM) information with an industry standard reliability design approach to establish the expected RAM of each of the three final candidate designs. Where new technologies have been proposed as part of these designs, estimates regarding the impact on reliability of the entire design were used, based on any similarities to existing technologies.

RAM parameters are calculated based on industry standard methods, in order to ensure a consistent basis for comparison. The following formulas adhere to IEEE Standard 762: Standard Definitions for Use in Reporting Electric Generating Units Reliability, Availability and Productivity.

\section{Availability}

The percentage of total time in a given period that a unit is functionally ready to serve load (ready reserve) or is serving load (fired or service hours) is defined as:

$$
\text { Availability }(\%)=\left(\frac{\text { Available Hours }}{\text { Unit Period Hours }}\right) \times 100
$$

Unavailability is the converse of availability and is equal to the percentage of total time that a unit is functionally unable to serve load, either due to a forced or scheduled outage.

Unavailability $(\%)=\left(\frac{\text { UnavailableHours }}{\text { UnitPeriod Hours }}\right) \times 100$

\section{Reliability}

The converse of Forced Outage Factor, Reliability is the percentage of total time in a given period that a unit is able to serve load, when not on outage associated with; a failure to start, an automatic or manual trip from a state of operation, or forced downtime initiated from a state of reserve.

$$
\text { Reliability }(\%)=\left(1-\frac{\text { Forced Outage Hours }}{\text { Unit Period Hours }}\right) \times 100
$$




\section{Failure Rate per Million Fired Hours}

The average number of forced outages (automatic or manual trip from a state of operation) that will be experienced in a million operating hours (fired or service hours) is defined below. The mathematical inverse of the FR/MFH is the Mean Time Between Failure (MTBF). The MTBF represents the average amount of operating time (fired or service hours) that a unit will run (serve load) before experiencing a forced outage (automatic or manual trip).

$$
\begin{aligned}
& \text { FailureRatePerMillionFired Hours }=F R / M F H=\left(\frac{\text { Numberof ForcedOutageTrips }}{\text { UnitService }(\text { Fired }) \text { Hours }}\right) \times 10^{\wedge} 6 \\
& \text { Mean Time Between Failure }=M T B F=\left(\frac{\text { Fired Hours }}{\text { Trips froma state of operation }}\right)
\end{aligned}
$$

\section{Starting Reliability}

The probability that a unit, which is classified as available, and in ready reserve, can be started, and be brought to synchronization within a specific period of time is defined below. An inability to start within the specified period and synchronize is considered a failure to start. However, repeated attempts to start without attempting corrective action are not considered additional failures to start.

Starting Reliability $(\%)=S R=\left(\frac{\text { Number of Successful Starts }}{\text { Number of Attempted Starts }}\right) \times 100$

\section{RESULTS AND DISCUSSION:}

The first step in evaluating the RAM Parameters of a new design is to first establish a baseline. This baseline must be a known technology with field experience and documented RAM statistics for a large enough sample size such that the statistics can be considered representative of the population. The candidate designs are compared to the baseline, and any deviation from the baseline must be evaluated for its impact on the overall plant RAM statistics. If this deviation is a new component or a new design, then that component or design must be subjected to a separate detailed failure analysis to determine its failure modes and expected life. In the absence of such an analysis, as is the case for this study, the failure characteristics must be estimated based on engineering judgment and on any similar existing components or designs.

The baseline is further broken down into its major components, with the contribution of each to the total unreliability and unavailability. Each component has its own failure rate and distribution, and the aggregate of all the components determines the overall unreliability and unavailability of the plant. Component-level field failure data for the period of 1992-2000 was obtained on samples of the existing GE gas turbine fleets from an external third-party company, which tracks and analyzes this data for the gas turbine industry. Data on the GE Heavy Duty 7F/FA was employed as the baseline for the 2-Shaft Heavy Duty Concept, and the another set of data on the GE LM6000 aeroderivative was employed as the baseline for both the Aeroderivative Concepts and Hybrid Concept candidate designs. A statistical distribution analysis was done using the LM6000 data to determine the distribution of units in the sample in relation to their respective RAM statistics 
The next step was to compare new design features with similar existing designs, using failure data from those similar designs to build a model for the candidate designs. Then the impact of the new features were determined on the overall RAM parameters of the plant. After this was completed for all new design features, the component characteristics were aggregated to determine the RAM statistics for each candidate design. A Distribution Analysis was made to see how the candidate designs stack up against existing actual fleet data. This analysis was then compared on the basis of: Plant Availability, Plant Reliability, Plant Starting Reliability, Plant Failure Rate per Million Fired Hours, Flange to Flange Reliability, Flange to Flange Reliability, Flange to Flange Starting Reliability, and Flange to Flange Failure Rates per Million Fried Hours for each candidate designs.

\section{SUMMARY:}

RAM analysis of the candidate designs at this stage using field data from operating units show that all of them are expected to have RAM statistics and service life on par with their existing baseline fleets. Since this evaluation was based upon engineering estimates of several new component designs, and not actual test data, the results of this evaluation must be considered preliminary in nature. There are some differences that can be observed between the three candidate designs, however, due to the nature of the input data, all three designs should be considered to be essentially equivalent at this time, and none of them could be eliminated from consideration as a possible final design based upon this RAM evaluation. 


\section{Task 3.3: Cost of Electricity Analysis}

\section{TASK OBJECTIVE:}

The contractor shall draw on results from Tasks 3.1 and 3.2 to calculate cost of electricity for the three or four candidate systems. The results for this Task will be a list of assumptions for the COE study and a table containing the expected COE, life cycle cost, operations cost, maintenance cost and capital costs for the candidate systems.

\section{INTRODUCTION/BACKGROUND:}

Cost of Electricity (COE) calculations were done as part of evaluation of the selected concepts in the market place. A Cost of Electricity model is developed based on mature prices for equipment, balance of plant (BOP), operation, maintenance, efficiency and fuel cost. Capital charge reflects the price of the generation equipment to the power producer whether independent (IPP) or electric utility (EUPG) or industrial generator (IPG).

Gas Turbine World Handbook 2000 catalogue prices were used to develop a correlation between product attributes and product catalogue prices. Once this was established, technology levels for products in the catalogue were aligned with class $\mathrm{E}$, class $\mathrm{F}$ and $\mathrm{G}$ machines. For an $\mathrm{H}$ machine, the price for a $\mathrm{G}$ machine was assumed. A subset correlation was developed for each class of machines by using aggregate values for product attributes.

An algorithm for typical maintenance in gas turbines (Heavy-duty and Aeroderivatives) was developed considering GE experience for market level prices for year 2000. The maintenance price includes: planned maintenance (supervision, labor and repair) unplanned maintenance, planned spare parts, unplanned spare parts, mobilization and contingency. The plant operation and routine BOP maintenance are not included.

The operation price model was developed using average operation price of gas turbine plants and includes: operator and routine BOP maintenance, overhead, contingency, subcontractors and materials.

Fuel prices were varied between $\$ 2$ to $\$ 5$ per MMBTU HHV due to the high volatility experienced in the last 2-3 years, and a possibility of continued volatility of these prices.

Hours of dispatch was also kept as a variable, as these will change from operator to operator, and from each FERC region to another, depending on the energy use patterns and availability of alternate power sources.

Typically, general usage of these gas turbines is dependent on ambient temperatures. When ambient temperatures increase, electricity demand increases; intermediate load and peaker machines will be brought on line. Typically peakers are turned on when the load cannot be satisfied by less-expensive sources of energy such as combined cycle power plants. These opportunities typically occur in summer when the ambient temperatures are high. In order to include the effects of ambient conditions in the cost of electricity evaluation, performance of the concepts was evaluated at $32.2{ }^{\circ} \mathrm{C}(90$ 
$\left.{ }^{\circ} \mathrm{F}\right) / 30 \% \mathrm{RH}$ in addition to the ISO $15{ }^{\circ} \mathrm{C}\left(59{ }^{\circ} \mathrm{F}\right) / 60 \% \mathrm{RH}$. The performance at $32.2{ }^{\circ} \mathrm{C} / 30 \% \mathrm{RH}$ condition was used at a nominal dispatch of 100 hours and the $15{ }^{\circ} \mathrm{C} / 60 \% \mathrm{RH}$ condition at 8000 hours. Performance of the concepts was linearly interpolated for dispatch hours between 100 and 8000 hours to perform the COE analysis.

\section{RESULTS AND DISCUSSION:}

A comparative assessment was made of the Cost of Electricity (COE) determined for each of the selected Candidate Concepts, and were then compared to both the aeroderivative and heavy frame type 1999 State-of-Art Engines. All configurations were compared on the basis of the following assumptions:

$\begin{array}{ll}\text { Evaluation term: } & 20 \text { years } \\ \text { Fuel: } & \text { Natural Gas } \\ \text { Fuel Cost } & \$ 4 / \mathrm{MMBTU}-\mathrm{HHV} \\ \text { Fixed Charge Rate: } & 16 \% \\ \text { Discount Rate: } & 10 \% \\ \text { Escalation: } & 3.0 \% / \text { year } \\ \text { Levelizing Factor } & 1.23\end{array}$

And each was assessed against 20 year Levelized COE's between 1000 to 8000 hours per year. Additionally, a similar assessment was made for fuel sensitivity at \$3/MMBTU-HHV.

\section{SUMMARY:}

Preliminary analyses of the COE for the selected candidates show that all the candidates meet or exceed $15 \%$ or greater COE reduction from 1999 State of the Art Technologies, as required by DOE program objectives. The COE, Capital Cost and O\&M reductions are broken down as follows:

\begin{tabular}{|c|c|c|c|}
\hline & \multicolumn{3}{|c|}{$(\%)$ Reduction } \\
\hline & Aero derivative & Hybrid & Heavy Duty \\
\hline Overall COE & $>15 \%$ & $>18 \%$ & $>24 \%$ \\
\hline Capital Cost & $>24 \%$ & $>29 \%$ & $>11 \%$ \\
\hline $\mathrm{O} \& \mathrm{M}$ & $>22 \%$ & $>29 \%$ & $>8 \%$ \\
\hline
\end{tabular}




\section{Task 3.4: Risk Analysis and Decision}

\section{TASK OBJECTIVE:}

The contractor shall take into account commercial and technical risks that may arise from the candidate systems. Risks may include ability to use multiple fuels, flexibility to have at least 400 starts per year, ability to be used for multiple applications including DOD, distributed generation, merchant plants and others. The contractor shall address environmental and competitive issues. Using the information developed in Tasks 3.1-3.4, a recommendation of the best aero-derivative system, the best heavy duty system, and possibly a hybrid system, shall be made.

\section{INTRODUCTION:}

Each of the selected design candidates has at least some evolutionary technology needs, and could potentially incorporate revolutionary technology. These more advanced technologies need development and demonstration to function satisfactorily to meet product requirements identified in Task 2.1. The identified technologies are illustrated in Table 3.4.1. The uncertainty in the development process, including resource needs to validate the technologies, represents technical risks to the development of NGGT product.

For the Aero-derivative, Heavy duty, and the Hybrid engine concepts, the objective of the team has been to minimize the technical risk by utilizing as many of existing components as possible. However all risk is still not mitigated, as the operating conditions, such as blade loading, are outside the experience base when, e.g., an inter-cooled engine design is considered with existing component designs.

As noted in the previous task a key technology that has to be developed is low NOx combustion technology that can meet $15 \mathrm{ppm}$ NOx emissions with the increased firing temperatures and operating conditions.

\section{RESULTS AND DISCUSSION:}

\section{Discussion of Technical Risk}

\section{Hybrid Concept Technical Risks}

The selected aeroderivative concept is based on the LM6000. The design pushes the experience in several areas. The inlet temperature to the (existing) core compressor is lower, as a result of an intercooler. While the inlet temperature is lower, the mass flow is up. The potential effect is an increase in blade loading in the compressor, leading to aeromechanical durability issues. Further, the operating pressure of the selected cycle is higher with an OPR of 40. The compressor case and the combustor case design would therefore need to be evaluated for durability, keeping in mind that the compressor discharge temperature is lower than that of the LM6000. 
A major risk item is the combustion system. The increase in firing temperature and the reduction in compressor discharge temperature results in a significant increase in combustor heat release within the combustor. This is also accomplished at a higher operating pressure (compared to the LM6000). Dry Low Emissions combustor designs executed to date have been affected by combustion driven pressure pulsations. If a severity parameter is defined for the design of Dry Low Emissions (DLE and DLN) combustors as

$$
\mathrm{S}=\mathrm{P} * \mathrm{Q}
$$

Where,

$\mathrm{S}$ is the severity parameter,

$\mathrm{P}$ is the operating pressure of the combustor in atm,

$\mathrm{Q}$ is the total heat release in the combustor, MW,

then the Severity of the Aero combustor for the LM6000 is at a value of S which is less than half that of the Hybrid Concept. This doubling of the severity parameter shows a significant need to develop and demonstrate stable combustor operation at the hybrid design operating conditions.

The high-pressure turbine design for the hybrid and the aero concepts is based on the LM6000. The operating pressure of this turbine is higher than the LM6000, as can be seen in Table 2.1.4. The heat transfer coefficients in turbulent flow are generally dependant on operating pressure to the power 0.8 . The increase in gas heat transfer coefficient will cause the temperature gradients in the turbine nozzle and blades to be higher. Note the intercooler will cause the cooling air temperature to drop, while the selected cycle also requires the firing temperature to rise by $93.3^{\circ} \mathrm{C}\left(200{ }^{\circ} \mathrm{F}\right)$. Higher thermal gradients will cause higher thermal stresses accompanied by a reduction in cyclic life. The turbine design analysis has to ensure that the thermal stresses are within acceptable limits commensurate with 400 starts per year and a 20 year life of the turbomachinery. The risk is lowered by the use of GE's New Product Introduction process, and use of 6 Sigma tools in executing the design and manufacturing processes.

The intermediate pressure turbine represents a lower level of risk in comparison to the combustor. The power turbine is also a new design and has the same level of risk as the intermediate pressure turbine. The risk of both of these components is lowered by the use of GE's New Product Introduction (NPI process) and through the use of 6 Sigma tools in executing design and manufacturing processes.

The intercooler represents a large volume of stored compressed air. The aeroderivative and the hybrid engine control system designs will have to include the effects of this large stored volume. Appropriate design modifications will be needed to account for the dynamic effects of the intercooler. When the engine is quickly accelerated, the intercooler thermal response may lag the rest of the engine. Analyses will have to be performed for loss of load transients to ensure that the power turbine and the core engine speeds do not exceed safe limits. On the durability side, the intercooler design will have to have cyclic life like the rest of the engine, i.e.: be capable of 400 starts per year with 20 years of useful life. 
$\underline{\text { Heavy Duty Concepts Technical Risks }}$

The primary technical risks associated with the development of any of the 2-shaft heavy duty concepts are two-fold. The first risk category is the development of a combustion system that delivers low NOx emissions, at a high firing temperatures and an overall pressure ratio of 40:1. This technology hurdle is shared with the aero-derivative and hybrid NGGT concepts. The second major technology risk is the development of the enabling technologies envisioned for an NGGT product. These technologies, and their associated risks, are described in Task 4 of this report. A near-term technology demonstration program where individual technologies were validated and introduced into the current GE product line would mitigate this risk in the interim time between now and when a domestic market materializes for the NGGT product.

The various component design needs were assessed on the basis of either that which requires new design, re-design of current components, or none required for each of the candidate configurations down selected. From this matrix, each concept risk area was then further assessed in terms of low, medium or high potential technical risk.

\section{Discussion of Market Risk Issues}

The most important factors affecting market potential for NGGT are (1) load growth, (2) fuel prices, and (3) the addition of new generating capacity.

\section{$\underline{\text { Load Growth }}$}

Electric demand has two components: peak demand and energy demand. Peak demand refers to the maximum amount of power that is required at any moment in time and is measured in gigawatts. Energy demand is the total amount of electric energy produced (or consumed) in a given year and is measured in gigawatt-hours. In the U.S. between 1973 and 1999, energy demand grew at an average annual compound growth rate (AACGR) of approximately $2.7 \%$ per year. ${ }^{2}$ NERC currently forecasts energy demand growth to be at a lower rate, approximately $1.9 \%{ }^{3}$ on average but with regional variations. NERC forecasts peak demand to grow at approximately the same rate.

Future load growth is uncertain. Year-to-year peak demand and, to a lesser extent, energy demand growth are depend on weather conditions. Long-term growth rates depend more on overall economic growth and changes in technology. Actual growth rates between now and 2005 may deviate significantly from those predicted, either positively or negatively. An error in overall growth rate of $+/-0.2 \%$ corresponds to a $7 \mathrm{GW}$ variation in the amount of capacity needed by 2005 .

Future demand may well be lower than predicted. The expansion of open power markets can be expected to spawn an increased presence of price-responsive loads (i.e. consumers that will voluntarily restrict their consumption in response to high prices). This behavior represents a significant departure from historical norms that generally held that short-term demand for electricity was essentially inelastic. Price responsive loads will have a much greater effect on peak demand than

\footnotetext{
${ }^{2}$ Based on annual net generation data published by EIA.

${ }^{3}$ NERC ES\&D (Energy Supply and Demand) 2000, April 2000.
} 
on energy demand, leading to a reduced need for installed capacity, but a smaller reduction in the total amount of energy being generated.

\section{$\underline{\text { Fuel Prices }}$}

Fuel prices are volatile. Last winter's experience clearly demonstrates how quickly natural gas prices can change. Coal, while generally less volatile than natural gas, has also experienced considerable price swings over the past few months.

The attractiveness of different generating technologies is highly influenced by the relative cost of fuel. At natural gas prices of less than about \$4.50/MMBTU HHV, coal-fired generation is generally less attractive than natural gas-fired technologies. If measurably higher natural gas prices become common, however, coal-fired generation can become a significant market force. Recent interest in coal-fired power plant studies demonstrates the potential swings that can occur as relative fuel prices change.

Modern coal-fired generation can be expected to find some niche markets, but will have limited penetration unless gas prices escalate significantly above the predicted level. Lower gas prices than predicted will have relatively little effect on competitiveness of the NGGT.

\section{Addition of New Generating Capacity}

New natural gas-fired power plants are being announced at unprecedented frequency. According to RDI NewGen ${ }^{4}$, developers have announced over $490 \mathrm{GW}$ of new capacity. While it is highly unlikely that all of the announced units will be built, approximately $150 \mathrm{GW}$ have already entered service or are under construction. Another $58 \mathrm{GW}$ are in "advanced development", a category established by RDI to capture plants that have made significant progress toward completion. These additions are almost entirely gas turbine-based technologies, in either simple or combined cycle configurations.

The GEPS NGGT market analysis considered two cases: one with $130 \mathrm{GW}$ of new capacity, and a second with $240 \mathrm{GW}$ of new capacity. Based on observed industry activity, the latter case appears more likely to occur. In this case, the addition of today's gas turbine technologies virtually eliminated all opportunities for economically displacing existing, low-efficiency generation. Consequently, NGGT success in a displacement market requires that it successfully compete with today's heavy duty machines rather than old steam boilers. The performance improvement projected for NGGT is not sufficiently large as to offset the capital investment expense to add new units where capacity is not required for reliability reasons. Consequently, NGGT will not benefit significantly from the displacement market. The amount of new generation planned is sufficiently large that there is little likelihood of this conclusion being altered.

There are a number of potential factors that could affect the market potential for NGGT, either positively or negatively.

Little investment is occurring in transmission infrastructure. Notwithstanding FERC's recent activity in the RTO arena, there is little evidence of any fundamental changes that would reverse this trend.

\footnotetext{
${ }^{4}$ RDI NewGen, July 2001.
} 
As a result, load pockets may emerge that cannot be adequately served by the existing bulk transmission system. These pockets are logical locations for distributed generation. To the extent that NGGT can be configured for distributed generation applications, it could find markets that are not fully captured in the GEPS assessment of the bulk power market. High efficiency (low emissions), high reliability, and low capital cost are important determinants for success in the distributed generation market. Competition in this market is likely to be stiff with the introduction of fuel cells and renewable energy technologies potentially entering the distributed energy market at about the same time as NGGT. These latter technologies will be especially competitive on the basis of efficiency and low variable cost, respectively, albeit at very high initial product cost. Consequently, continued focus on initial NGGT product cost will be required to maintain this competitive advantage.

As noted above, market-based electricity pricing may give rise to a price-responsive consumer segment. If price elasticity becomes significant, the need for new generating capacity will be reduced, affecting market potential for all future generation.

Cogeneration and combined heat and power (CHP) applications are relatively limited in the U.S. Low electricity prices for industrial consumers limit the potential for cogeneration expansion. Changes in technology, nonetheless, may result in new niche markets emerging. Again, competition in this area may be stiff - technologies like the solid oxide fuel cell with very high outlet temperatures may also compete.

All of these factors were then reflected in a commercial risk comparison of the three candidate concept designs against DOE goals of: Ability to Use Multiple Fuels, Flexibility to Start $>400$ times per year, Ability to be Used by Multiple Users - such as DOD and Distribution Generation applications, Environmental Issues - primarily emissions related, and GE concerns of competitive issues associated with market conditions and current product offerings.

\section{$\underline{\text { SUMMARY: }}$}

This feasibility study has employed the Six Sigma evaluation process to identify the aero/heavy duty hybrid as the GE NGGT product concept that best addresses the CTQ's identified by the DOE, and independently validated by GE. A number of risks have also been identified that would require mitigation in order to drive NGGT product development beyond the feasibility study stage. Predominant among these risks are market risk associated with rapid, recent regulatory changes in the domestic power generation market; and technical risk associated with the development of new NGGT-enabling technologies. In this latter category are the risks associated with the development of high pressure ratio combustion technology.

GE's proposal for a Technology-Focused NGGT program would be instrumental in mitigating those risks by delaying an NGGT product development program until a domestic market for the NGGT becomes more evident, and by validating NGGT technologies within the existing GE product line. Significant Public Benefit would also ensue via this strategy, as will be elucidated in a subsequent section. 


\section{Task 4: Enabling Technologies}

Identify near term technology developments based on current state of art and develop a roadmap.

\section{Task 4.1: Identification of Technology Needs}

\section{TASK OBJECTIVE:}

The contractor shall identify all enabling technology needed to develop the best aero-derivative gas turbine system, the best heavy duty gas turbine system, and possibly the best hybrid system by a cross-functional team including design, manufacturing, materials and systems engineers. The contractor shall complete a list of necessary technology, the associated levels of impact, and potential development challenges. The contractor shall also identify needs in the areas of materials, combustion, sensors/controls, computing, heat transfer, aero in addition to other areas. Define areas for both pre-competitive and competitive research needs and who could best perform the research (labs, university etc).

\section{INTRODUCTION:}

The Next Generation Turbine does not have to push the state of the art to achieve most of the DOE objectives except in the areas of combustion and RAM. However, there are several technologies that can be applied to an NGGT. Since the market opportunity will slip approximately 5 years, it is recommended that these technologies be developed in the interim.

Realistically, it is preferable to develop and demonstrate individual new technologies before attempting to commercialize multiple new technologies in a revolutionary product. Many, if not all of these technologies may be candidates for demonstration on GEPS existing products as they are developed. System payoff of candidate technologies will be quantified using the "F" heavy duty product as a benchmark.

Feedback from the customers, IPP, EUPGs has identified the need to improve the reliability, and availability of the engines as a critical need. Thus sensors and control systems that contribute to the lack of availability and reliability will have to be developed further.

\section{RESULTS AND DISCUSSION:}

\section{NGGT Enabling Technologies}

A list of technologies appropriate for incorporation in an NGGT product concept has been defined based on the prior task efforts to evaluate the selected candidate concepts.. This list of required technologies has been assessed against the component to which it is applicable, the thermodynamic simple cycle impact of the technology, and the challenges associated with the development of the technology. The simple cycle impact of each technology was evaluted as a percentage from nominal in terms of output (MW), Heat rate (HR) and surge margin. 
There are developmental challenges associated with each of the technologies identified, as most are not mature and ready for product integration. Many will require significant development and validation of new design practices and product level integration. Some technical disciplines will need furtherance of design capability hinging upon the expansion of existing experimental data with which new numerical modeling approaches can be validated. Some of these areas are currently being looked at by industry and have been identified as areas needing further investment resources to advance the state of the art. In these situations, cost shared funding with DOE can be crucial to the initiation of additional business investment.

\section{Technology Research Needs - Pre- and Post Competitive}

A list of necessary technology, the associated levels of impact, and potential development challenges was formulated and elucidated, encompassing areas of materials, combustion, sensors/controls, computing, heat transfer, aero in addition to other areas. Areas of both pre-competitive and competitive research needs, and who could best perform the research (labs, university etc) was identified. A composite list of the identified critical technology development needs for successful introduction of an NGGT product to the market place has been developed as part of this task effort.

\section{Hybrid Concept 3 With Application of Identified Enabling Technologies}

As an exercise to demonstrate what the application of the identified technologies identified above might translate to in a $\sim 2010+$ NGGT type product, all of the appropriate, usable technologies have been applied to the top rated hybrid concept 3 design. The assumption is that in this time period all of these technologies have been demonstrated, and would be available for commercial application.

For the top QFD rated Hybrid Concept 3 design, this would result in improvements in performance and increased power output of the gas turbine engine. Improved sealing in the compressor and reduced parasitic flows increase the flows available in the cycle to develop power. A bigger increase in performance results by permitting the firing temperature to be increased to $\mathrm{H}$ class levels.

The performance of the Hybrid Concept 3 with upgraded technology was evaluated against the basic DOE program goals of increased SC efficiency, net plant Output, Turn Down ration improvements, time to Start, NOx Emissions, and Start Capability. The greatest improvement were found to be a $15 \%+$ increase in engine output of the Hybrid Concept 3, but less than $1 \%$ increase in efficiency. However, due to the increased new technology technical risk effects on reliability, availability and maintainability this will not immediately translate into reductions in capital cost of the engine and COE. 


\section{SUMMARY:}

GE has identified the enabling technologies required for an NGGT product offering, including design, manufacturing, materials and systems engineering considerations. A list of necessary technology, the associated levels of impact, and potential development challenges has been formulated and elucidated, encompassing areas of materials, combustion, sensors/controls, computing, heat transfer, aero in addition to other areas. Areas of both pre-competitive and competitive research needs, and who could best perform the research (labs, university etc) has been identified.

Additionally, GE has attempted to provide a glimpse forward into the 2009+ time frame to indicate what impact these identified enabling and revolutionary technologies might produce in the NGGT Study top QFD-rated Hybrid Concept 3 candidate. 


\section{Task 4.2: Develop Roadmap for Development of Technology Needs}

\section{TASK OBJECTIVE:}

In this Sub-Task, the cross-functional team shall develop the road map that will give contractor the needed technology for the selected gas turbine systems. The team shall also incorporate the needs into contractor's internal Multi-Generation Technology Plan (MGTP), with a schedule for timely implementation. Recommend modification to system level goals (i.e. efficiency, cost etc) that may maximize public benefit. Identify the government role by providing evidence that industry would not do this without the DOE, and describe why government funds are needed to provide the public benefit.

\section{INTRODUCTION:}

A number of enabling technologies were envisioned to enhance the ability of the NGGT product concept, to meet the DOE's objectives for increased efficiency, reliability, emissions performance, etc, over today's product offerings. These technologies are shown in road map form in Figure 4.2.1. This technology plan should be embarked upon in the near term in order to develop an NGGT product in the 2006 frame duty.

\section{RESULTS AND DISCUSSION:}

\section{Technology Roadmap}

As part of this subtask, a cross-functional team has identified the necessary enabling technologies and developed a roadmap that will give GE the needed technology for the selected NGGT gas turbine systems. This technology development roadmap includes areas that are currently identified with some development activity in process, as well as those areas that still need to be addressed. A plan for the timely execution of the technology roadmap was also developed with each of the identified technological areas assessed on a timeline for the next decade, including denoted milestones necessary to achieve the level of advance necessary for an NGGT product circa 2010. This information is considered GE Company proprietary and has not been included in this public report.

Since a domestic market for the NGGT product will not be established for several years, the enabling technologies identified should be developed and validated for migration into the installed base of Fclass power generation assets. . This will provide significant Public Benefit that would otherwise not be generated, due to the technical risks and cost associated with developing these technologies from the conceptual stage to product implementation. 


\section{SUMMARY:}

A cross-functional team has developed the roadmap that will give GE the needed technology for the selected NGGT gas turbine systems. A plan for the timely execution of the technology roadmap has also been developed. Since a domestic market for the NGGT product will not be established for several years, these technologies should be developed and validated for migration into the installed base of F-class power generation assets. This will provide significant Public Benefit that would otherwise not be generated, due to the technical risks and cost associated with developing these technologies from the conceptual stage to product implementation. These Public Benefits include reduced energy consumption, reduced life-cycle power-production costs, and more efficient land usage. A detailed quantification of these Public Benefits was created as part of Task 5 of this feasibility study. 


\title{
Task 5: Analysis of Benefits
}

\section{Task 5.1 : Analysis of Support for Vision 21}

\author{
TASK OBJECTIVE:
}

The contractor shall perform an analysis of how the selected systems support the DOE Vision 21 goals of high efficiency power production with fuel-flexible, low-emissions systems and coproduction of alternate product streams such as liquid fuels, heat and syngas/H2.

\section{INTRODUCTION:}

Technologies identified in Task 4 will ultimately enable a hybrid aeroderivative that exceeds the DOE stated objective in several performance categories. Incorporation of these technologies into other GEPS products will also offer several enhanced performance alternatives for the Vision 21 "Power Module".

\section{RESULTS AND DISCUSSION:}

The primary objective of Vision 21 plants is to effectively remove all environmental concerns associated with the use of fossil fuels for producing electrical power, liquid transportation fuels, and high-value chemicals from fossil feedstocks - alone or in combination with biomass, and / or opportunity feedstocks such as petroleum coke, Refuse-derived Fuel, Municipal Solid Waste, and sewage sludge. These plants are likely to be large stand-alone facilities of 30Mwe or larger as part of a central station facility located at or near a large industrial consumer's site using fossil fuel based feedstocks or combinations of other opportunity feedstocks.

The NGGT concepts identified by GE generally support Vision 21 goals of high-efficiency power production, via fuel-flexible, low-emissions subsystems, especially when included as part of an IGCC plant configuration. While this would appear to be a excellent application of NGGT concepts to a Vision 21 system, specific DOE NGGT goals are found to be compromised.

Taking today's gas turbine-based IGCC plant as an analogue of tomorrow's Vision 21 plant marked differences between a limited number of CTQ's pertaining to an NGGT product, and those that define the Vision 21 power plant of 2015 were noted. The most apparent of these differences is the NGGT requirement for fast starts, and a related CTQ, the capability of 400+ starts per year, an IGCC plant requires approximately four days to come on line. This is in direct conflict with both the requirement for fast starts, and with the requirement of 400 starts per year associated with NGGT. Taking the IGCC plant analogy a step further, it can be noted that the Air Separation Unit of an IGCC plant is the limiting component of the plant's turn-down capacity. Consequently, the NGGT CTQ on gas turbine turn-down capability to very low levels of output does not mesh with the systems-level CTQ's of an IGCC plant, and by proxy, to a Vision 21 power plant. Put another way, the CTQ on gas turbine turn-down capacity will probably not be capitalized upon in a Vision 21 context. While direct application of any of this study's selected NGGT product concepts does not appear to be a good fit, the NGGT enabling technologies identified herein, and the proposed development and validation on 
existing products, does provide "stepping stone" technology improvements to a potential future Vision 21 specific product.

The DOE publication "Development of Technologies and Analytical Capabilities for Vision 21 Energy Plants," describes potential spin-off technologies that would result from the Vision 21 program. In particular, "...improved low-cost manufacturing technologies for high-technology components, advanced turbinelengine combustion, and materials technologies for enhanced system efficiency and performance, and improved materials for service under aggressive high-temperature conditions,..." were therein cited as technologies that are anticipated to result, possibly as early as 2005, from R\&D supported by the Vision 21 solicitation. The technologies to be developed in support of the NGGT are in large measure in support these Vision 21 goals.

Examples of Vision 21 / NGGT technology synergy can be taken from the area of advanced turbine combustion which contribute to the Vision 21 goals of highly-efficient, ultra-low-emission combustion of multiple fuel streams, with reduced component cost and complexity, and improved reliability.

Other examples of how Vision 21 goals mesh with NGGT technology development is in the materials and castings technologies, which address the need for low-cost manufacturing techniques for hightechnology components. These programs seek to increase the manufacturing yield, and thus reduce the cost, of manufacturing turbine buckets. Similarly, other materials development initiatives seek to apply specific alloys as a means of cost-reduction. These cost reductions can result from increased throughput, more dependable delivery, and higher casting yield. Further examples of increased efforts in advanced turbine/engine materials technologies would enhance system efficiency and performance for service under the aggressive, high-temperature conditions anticipated to be characteristic of Vision 21 plants.

\section{SUMMARY:}

In summary, the enabling technologies required for NGGT are anticipated to be scalable to the large, combined-cycle powerplants envisioned in the Vision 21 concept. Further, these technologies are amenable to the modular, building-block paradigm that is central to Vision 21, wherein power, chemicals, and fuel-conversion technology modules are integrated into systems that achieve the needed level of performance at affordable costs. Lastly, the NGGT system concepts described in this report are representative of the "...systems that integrate multiple technologies in order to achieve step improvements in performance and cost...," as articulated in the Vision 21 solicitation.

\footnotetext{
${ }^{5}$ (Financial Assistance Solicitation Number DE-PS26-99FT40578)
} 


\section{Task 5.2: Analysis of Public Benefits}

\section{TASK OBJECTIVE:}

The contractor shall perform an analysis of, and report on, how the selected systems provide significant public benefits through emissions reduction, increased system reliability, reduced fuel and electricity cost, and increased U.S. job market potential.

\section{INTRODUCTION:}

\section{Societal Benefits Analysis}

An analysis has been performed to assess the societal benefits of the NGGT program, and contrast them with the level of benefits that were outlined in the AD Little (ADL) study that had been previously executed for DOE in 1999.

As the reader may recall, GE had projected that the size of the NGGT Market Segment in 2005 would be about 0-30 GW for the Displacement market segment (more near zero), and about $14 \mathrm{GW}$ per year for the Load-growth-driven market segment.

\section{Displacement Market Segment}

Based upon the level of order and commitments for new high-efficiency (7F class) Combined-cycle power plants in the USA, the GE's analysis indicates that the NGGT's commercial introduction will occur too late to participate in the $27 \mathrm{GW}$ Displacement market segment. Thus, there would be no societal benefits attributed to the NGGT Program as a result of the displacement market.

\section{Load-growth-driven Market Segment}

In the GE market assessment, GEPS had projected that the NGGT technology could capture about 14 GW per year of the load-growth-driven market for new power plants. This market would not materialize until the USA regional reserve margins have fallen back to a need-based level, following the large influx of additional capacity that is currently on order, or being installed. For simplicity, we have assumed that this would occur in the 2005 time frame, to coincide with the introduction of the NGGT product. Table 5.2.1 contains other assumptions applied in this study. 
Table 5.2.1: Societal Benefits Assumptions

\begin{tabular}{|c|c|c|c|c|c|c|}
\hline & Average & Averag & Emissions - lbs/M & & & \\
\hline S/C GT & 12000 & & 0.2 & 0.0006 & 110 & \\
\hline NGGT & 7893 & & 0.0075 & 0.0006 & 110 & \\
\hline 207FA CC & 6600 & & 0.0075 & 0.0006 & 110 & \\
\hline Oil Steam & 11000 & & 0.3 & 0.5 & 150 & \\
\hline Gas Steam & 11000 & & 0.25 & 0.0006 & 110 & \\
\hline Coal Steam & 10500 & & 0.4 & 1.3 & 150 & \\
\hline Years of Analysi & $\begin{array}{l}2005 \\
\text { Coal }\end{array}$ & $\begin{array}{l}2015 \\
\text { Oil }\end{array}$ & $\begin{array}{l}11 \\
\text { Gas }\end{array}$ & & & \\
\hline $\begin{array}{l}\text { Fuel Price } \\
\text { \$/MBtu- 2001\$ }\end{array}$ & 1.40 & $\begin{array}{l}3.10 \\
\% \text { GT }\end{array}$ & $\begin{array}{l}3.10 \\
\text { Avoided Energy } \\
\text { \% ST-Oil }\end{array}$ & $\%$ ST-Gas & $\begin{array}{l}\% \text { ST- } \\
\text { Coal }\end{array}$ & $\% \mathrm{CC}$ \\
\hline $\begin{array}{l}\text { GW of } \\
\text { Displacement }\end{array}$ & $\mathbf{0}$ & NA & NA & NA & NA & NA \\
\hline $\begin{array}{l}\text { GW of growth } \\
\text { market }\end{array}$ & 13.5 & $2 \%$ & $9 \%$ & $11 \%$ & $0 \%$ & $78 \%$ \\
\hline $\begin{array}{l}\text { Capacity Factor } \\
\text { for NGGT }\end{array}$ & $77 \%$ & \multicolumn{5}{|c|}{ Average for 10 years } \\
\hline
\end{tabular}

\section{RESULTS AND DISCUSSION:}

The installation of $14 \mathrm{GW}$ of NGGT per year will result in the displacement of existing capacity in the following sequence: first, Simple-cycle Gas Turbines, followed by Fossil-steam Oil and Gas-fired power plants, and then, lastly, less-efficient, older-model combined cycle power plants. The level of associated societal benefits, in terms of fuel usage, fuel cost, and emissions is summarized in Tables 5.2.2 and 5.2.3, below, wherein several levels of NGGT efficiency are assumed $(48 \%, 60 \%$ and an $80 \%$ case). One of the most obvious take-aways from Tables 5.2.2 and 5.2.3 is that the NGGT is not able to achieve the level of Primary Energy savings as suggested in the AD Little report - even under an extremely generous assumption of $80 \%$ efficiency. In terms of Fuel Cost savings, the NGGT is able to more closely reach the ADL numbers in the $48 \%$ and $60 \%$ efficiency cases, and it is able to surpass the ADL numbers in the $80 \%$ case. This closer match is due to a higher gas price assumption in our analysis than the ADL analysis. Regarding power plant emissions, the NGGT is able to, at best, reach about $50 \%$ of the level of emissions reduction the ADL report had projected as illustrated in Table 5.2.3. 
Table 5.2.2: Primary Saving with NGGT Program

\begin{tabular}{|c|c|c|c|c|c|c|c|}
\hline \multicolumn{7}{|c|}{$\begin{array}{l}\text { Primary Energy - (trillions of Btu) } \\
\text { Total Market }\end{array}$} & \multirow[b]{2}{*}{$\begin{array}{l}\text { ADL } \\
11 \text { years }\end{array}$} \\
\hline & 1 Year & 11 years & 1 Year & 11 years & 1 Year & 11 years & \\
\hline Total & 64 & 701 & 117 & 1,288 & 350 & 3,849 & 4,900 \\
\hline$\%$ of AD Little & & $14 \%$ & & $26 \%$ & & $79 \%$ & \\
\hline \multicolumn{8}{|c|}{$\begin{array}{l}\text { Fuel Cost Savings - (Millions of 2001\$) } \\
\text { Total Market }\end{array}$} \\
\hline & \multicolumn{2}{|c|}{48 \% Efficiency } & \multicolumn{2}{|c|}{$60 \%$ Efficiency } & \multicolumn{2}{|c|}{$80 \%$ Efficiency } & \\
\hline & 1 Year & 11 years & 1 Year & 11 years & 1 Year & 11 years & $\begin{array}{c}\text { ADL } \\
11 \text { years }\end{array}$ \\
\hline Total & 197 & 2,172 & 363 & 3,992 & 1,085 & 11,932 & 6,900 \\
\hline$\%$ of AD Little & & $31 \%$ & & $58 \%$ & & $173 \%$ & \\
\hline
\end{tabular}

Table 5.2.3: Emissions Savings with NGGT Program

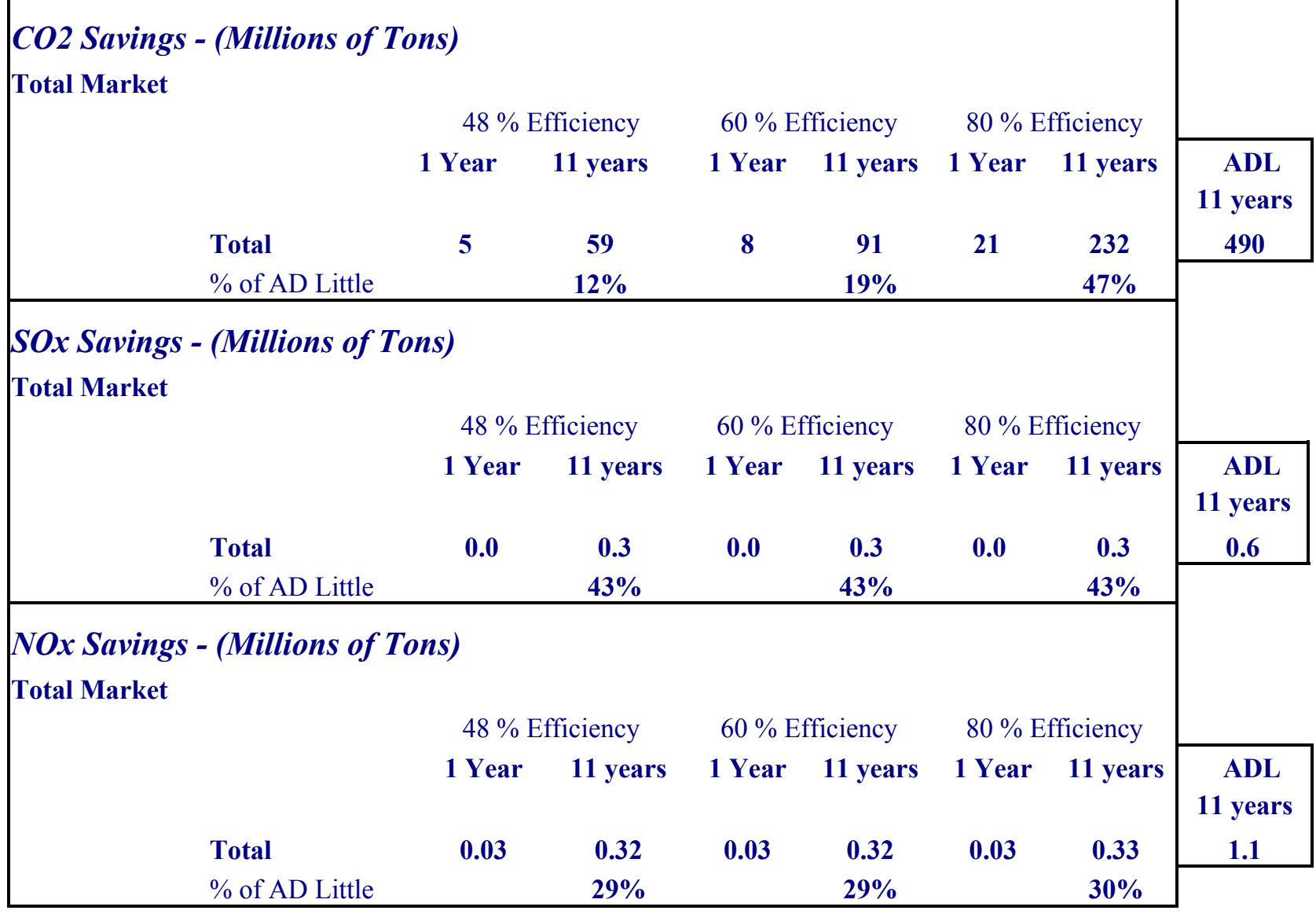




\section{Necessary Measures to Attain ADL Projected Societal Benefits}

For the NGGT program to reach the level of societal benefits that the ADL report had shown, it would be necessary for the NGGT technology to displace fossil-coal fired steam power plants. To do this, a calculation is shown in Table 5.2.4 illustrating that it would require NGGT to operate in the $75 \%$ efficiency range. Obviously this would require NGGT to run in a Cogeneration environment to achieve this level of efficiency. Even at this level of efficiency, the NGGT would only exceed the coal-steam power plant in dispatch cost, but would not generate any monetary savings to pay for the capital cost of the power plant.

Table 5.2.4: Heat Rate Needed to Displace Coal-fired Capacity.

\begin{tabular}{|c|c|c|c|}
\hline \multirow[t]{4}{*}{ Coal } & Heat Rate & \multicolumn{2}{|c|}{ 10,500BTU/kWh } \\
\hline & Fuel Price & 1.3 & \$/MMBtu \\
\hline & Variable O\&M & 6 & \$/MWh \\
\hline & Total Cost & 19.65 & \$/MWh \\
\hline NGGT & NGGT Var. O\&M & 3 & \$/MWh \\
\hline & Gas price & 3.3 & \$/MMBtu \\
\hline & Heat Rate & & \\
\hline & $\begin{array}{l}\text { Needed to } \\
\text { displace coal }\end{array}$ & 5,045 & BTU/kWh \\
\hline & (afficiency of: & $75 \%$ & \\
\hline
\end{tabular}


Table 5.2.5: Public Benefits of Migrating NGGT Technologies to the F-class Installed Base.

\begin{tabular}{|c|c|c|c|c|}
\hline Public Benefit & $\begin{array}{l}\text { ADL Report } \\
\text { (1999) }\end{array}$ & $\begin{array}{l}\text { Application of } \\
\text { NGGT } \\
\text { Technology to } \\
\text { GE F-class } \\
\text { Fleet }\end{array}$ & $\begin{array}{c}\text { NGGT } \\
\text { Product Only } \\
-2007 \\
48 \% \text { Simple } \\
\text { Cycle } \\
\text { Efficiency }\end{array}$ & $\begin{array}{l}48 \% \text { NGGT + } \\
\text { Application of } \\
\text { NGGT } \\
\text { Technology to } \\
\text { GE F-class } \\
\text { Fleet }\end{array}$ \\
\hline $\begin{array}{l}\text { Primary Energy Savings, T } \\
\text { BTU/Year }\end{array}$ & 445 & 44 & 197 & 241 \\
\hline Fuel Cost Savings, \$MM/Year & 627 & 153 & 64 & 217 \\
\hline CO2 Savings, M Tons/Year & 45 & 3 & 5 & 8 \\
\hline SOx Savings, M Tons/Year & 0.0545 & 0. & 0. & 0. \\
\hline NOx Savings, M Tons/Year & 0.1 & 0. & 0.03 & 0.03 \\
\hline Land Use Savings, Acres & & 33 & 0. & 33 \\
\hline Improved Availability (\$MM) & & 1,006 & 0. & 1,006 \\
\hline
\end{tabular}

Table 5.2.5 contains the projected annual public benefit of incorporating NGGT technologies into the NGGT and the GE F-class installed fleet of power generation assets. These calculations were based on assumptions of reasonable penetration of the GE installed base projected to be extant by 2005 , simple cycle / combined cycle capacity factor estimates, natural gas fuel cost of \$3.5/MBTU, and an increase of availability of $1.4 \%$. Specifically, the table compares the benefits of an NGGT product as projected by ADL in 1999, to those attainable by migrating NGGT technologies into a reasonable fraction of the F-class fleet. The table also compares the societal benefits of a $48 \%$ efficient SC NGGT product, and, lastly, the combined benefit attained by incorporating NGGT technologies into both an NGGT product, and into a portion of the GE F-class installed base.

The reader will note that the ADL-projected levels of benefits were still not attained, even by incorporating NGGT technologies into the F-class GE installed base. This substantiates GE's contention that market conditions had changed dramatically between the time of the ADL study (1999), and the time frame of GE's internal market study (2001).

Nonetheless, the table indicates that migration of NGGT technologies to the F-class installed base can significantly augment the public benefit attainable through the NGGT program. The available energy savings and the associated fuel cost savings are particularly significant, and, when combined with the value of increased availability afforded by NGGT technologies, amount to a total benefit of $\$ 1,223 \mathrm{MM}$. Further, the land use savings available by incorporating NGGT technologies into the Fclass amount to 33 acres, or nearly enough land for three typical combined-cycle power plants. 


\section{Summary}

In summary, it appears that rapid recent change within the power generation regulatory environment, and the resulting "bubble" of gas turbine orders, has altered the timing and relative significance associated with the conclusions of the ADL study upon which the original DOE NGGT solicitation was based. At the market level that GE has projected for NGGT, it would be extremely improbable that the level of societal benefits that ADL has suggested for the NGGT program could be achieved.

However, an investment by DOE to develop NGGT technologies near term $(\sim$ \$23MM/year, see Table 7.1) for validation and migration into a reasonable fraction of the installed base of GE F-class products could be leveraged into a $\$ 1.2 \mathrm{~B}$ Public Benefit, with the greatest benefits resulting from RAM improvements. Not only is there a monetary Public Benefit, but there is also a benefit in terms of reduced energy consumption, and reduced power plant land usage.

This technology-focused approach provides benefits not originally envisaged by the DOE. Further, it provides a roadmap for the validation and maturation of NGGT technologies that mitigates the risk associated with the longer-term development an NGGT product. 


\section{Task 6: Ability to Serve Multiple Users}

\section{TASK OBJECTIVE:}

The contractor shall show how the chosen gas turbine systems will serve multiple needs and applications in the marketplace. Of key interest is how each system will benefit a wide variety of users including the merchant market, distributed generation, and possible military power generation applications, among others. The results will be presented in the Final Report.

\section{INTRODUCTION:}

Table 6.1 contains a relative comparison of the applicability of the top-ranked NGGT concepts for the following market segments: Power Generation, Distributed Generation, and Military Application. These segments are further delineated into Simple Cycle, Combined Cycle, Co-generation, and Mechanical Drive sub-segments.

\section{$\underline{\text { Ability to be Used for Multiple Applications }}$}

Product concepts ranked "H," for high, are considered to be highly competitive for a particular application; those ranked "M," for moderate, are considered to be moderately competitive, and lastly, those ranked "L" are considered to be not likely to be applied to a particular segment.

Table 6.1: Applicability of NGGT Concepts Across Several Market Segments

\begin{tabular}{|l|c|c|c|c|c|c|c|c|c|c|c|c|}
\hline \multicolumn{1}{|c|}{ Concept } & \multicolumn{3}{|c|}{ Power Generation } & \multicolumn{3}{c|}{ Distributed Generation* } & \multicolumn{4}{c|}{ Military Application* } \\
\hline & SC & CC & COGEN & MD & SC & CC & COGEN & MD & SC & CC & COGEN & MD \\
\cline { 2 - 12 } & & & & & & & & & & & & \\
NGGT Aero Concept & H & L & M & L & H & L & M & L & M & L & M & L \\
NGGT Hybrid Concept & H & L & M & L & H & L & M & L & M & L & M & L \\
2-Shaft Heavy Duty & H & L & M & M & M & L & M & M & L & L & M & L \\
\hline
\end{tabular}

* The Distributed Generation category is viewed here as transmission-limited Distributed Generation in the 1 to $100 \mathrm{MW}$ size range.

** Typical Military shipboard applications call for Gas Turbine output in the 22-30 MW size range, which is not addressed by this program. Further, the CTQ's in this segment for high efficiency at part load (i.e. 20-35\% load) for loiter, and also high efficiency at peak power for combat / deployment would drive design differences in an NGGT product that would conflict with the CTQ's of the other segments.

The 2-shaft heavy duty concept benefits from its high cycle pressure ratio in the form of high simplecycle efficiency, and is thus most is most applicable to Simple-Cycle power generation segment. Its low exhaust temperature makes it relatively less applicable to the Combined-Cycle segment. The exhaust temperature is high enough, however, to make it moderately applicable in the Cogeneration segment. The large footprint required by the two-shaft arrangement probably makes it inappropriate for shipboard applications. 


\section{SUMMARY:}

GE has shown how the chosen gas turbine systems will serve multiple needs and applications in the marketplace. In particular, how each system will benefit a wide variety of users including the merchant market, distributed generation, and possible military power generation applications, among others. 


\section{Task 7: Cost Plan for System Development}

\section{TASK OBJECTIVE:}

The contractor shall develop a plan outlining the estimated budgetary cost that would be required for development of the systems selected. Format the Cost Plan on fiscal basis by $\$ / y r$ of DOE funding needs and industry cost share. Discuss leveraged dollars from other government agencies.

\section{INTRODUCTION/BACKGROUND:}

GE's response to this task is somewhat complicated by the results of GE's independent market study, which concluded that there is a limited near-term market for an NGGT product offering. This is in contrast to the findings of the AD Little study, which inspired the NGGT solicitation. Irrespective of this conflict, the program development costs of the leading GE NGGT product concepts are provided below. The DOE cost share amount is predicated upon GE's desire to mitigate commercial risks by containing introductory product development costs.

In lieu of proposing the development of an NGGT product offering directed toward near-term markets, GE has proposed that the DOE fund in Phase II of this solicitation the development of a number of NGGT-enabling technologies that would eventually be incorporated into an NGGT product. Near-term, these technologies would provide Public Benefit by enhancing products currently marketed by GE. DOE cost share for the development of these enabling technologies is provided below as Table 7.1. A spending profile for the Aeroderivative and Hybrid programs appears as Table 7.2 and the Heavy Duty 2 Shaft Program as Table 7.3.

\section{RESULTS AND DISCUSSION:}

The development program cost and duration for each of the three leading product concepts was assessed.

Table 7.1: Development costs for the selected concepts and enabling technology program

\begin{tabular}{|l|c|c|c|c|c|}
\hline Concept & \multicolumn{3}{|c|}{ Costs (\$MM) } & Duration & $\begin{array}{l}\text { Yearly Cost } \\
\text { To DOE }\end{array}$ \\
\hline & Program & GE Share & DOE Share & Months & \$MM/Yr \\
\hline $\begin{array}{l}\text { Hybrid } \\
\text { Concept 3 }\end{array}$ & C & C & C & C & C \\
\hline $\begin{array}{l}\text { Aero } \\
\text { Concept 3 }\end{array}$ & C & C & C & C & C \\
\hline $\begin{array}{l}2 \text { Shaft Heavy } \\
\text { Duty concept 3 }\end{array}$ & C & C & C & C & C \\
\hline $\begin{array}{l}\text { Enabling } \\
\text { Technologies }\end{array}$ & 154 & 62 & 92 & 48 & 23 \\
\hline
\end{tabular}

Note: 1) DOE Cost Share is based on 60\% for Technology Programs and 34\% for Product Programs 2) "C “ above denotes GE Confidential Information 
Table 7.2: Spending Profile for Aero-derivative and Hybrid Engine Programs

\begin{tabular}{|l|ccccc|c|}
\cline { 2 - 7 } \multicolumn{1}{c|}{} & \multicolumn{7}{c|}{ Year into Program } & Total \\
\hline Program Element & 1 & 2 & 3 & 4 & & C \\
\hline Technology Development & $\mathrm{C}$ & $\mathrm{C}$ & $\mathrm{C}$ & & $\mathrm{C}$ & $\mathrm{C}$ \\
Product Development & & $\mathrm{C}$ & $\mathrm{C}$ & $\mathrm{C}$ & $\mathrm{C}$ & $\mathrm{C}$ \\
\hline $\begin{array}{l}\text { Spending per year } \\
\text { DOE Cost Share }\end{array}$ & 10 & $\mathrm{C}$ & $\mathrm{C}$ & $\mathrm{C}$ & $\mathrm{C}$ & \\
\hline
\end{tabular}

Note: 1) All numbers above are \$MM

2) "C “ above denotes GE Confidential Information

Table 7.3: Spending Profile for Heavy Duty 2 Shaft Engine Program

\begin{tabular}{|l|ccccc|c|c|}
\cline { 2 - 7 } \multicolumn{1}{c|}{} & \multicolumn{5}{c|}{ Year into Program } & Total \\
\hline Program Element & 1 & 2 & 3 & 4 & 5 & \\
\hline Technology Development & $\mathrm{C}$ & $\mathrm{C}$ & $\mathrm{C}$ & $\mathrm{C}$ & & $\mathrm{C}$ \\
Product Development & $\mathrm{C}$ & $\mathrm{C}$ & $\mathrm{C}$ & $\mathrm{C}$ & $\mathrm{C}$ & $\mathrm{C}$ \\
\hline Spending per year & $\mathrm{C}$ & $\mathrm{C}$ & $\mathrm{C}$ & $\mathrm{C}$ & $\mathrm{C}$ & $\mathrm{C}$ \\
$\begin{array}{l}\text { DOE Cost Share } \\
\quad(960 \% \text { Tech \& 34\% Prod) }\end{array}$ & 34.1 & 34.1 & 34.1 & 34.1 & 15.5 & \\
\hline
\end{tabular}

Note: 1) All numbers above are \$MM

2) " $\mathbf{C}$ “ above denotes GE Confidential Information

\section{$\underline{\text { SUMMARY }}$}

GE's proposed NGGT technology development initiative would develop and validate technologies that would enable an NGGT product to meet the CTQ's proposed by DOE and corroborated in this feasibility study. By delaying the development of the NGGT product, it is likely that continuing load growth will provide a ready market for the NGGT, when it is introduced. Potential program costs, with spending profiles, for the development of the selected candidate systems have been defined, along with the importance of DOE future enabling participation. In the meantime, the development and integration of NGGT technologies into the current GE product line will provide the near-term Public Benefits that the NGGT program originally set out to achieve. 


\section{$\underline{\text { References }}$}

1) "Strategic Evaluation of Needs and Opportunities for U.S. Mid-Sized Gas Turbines in Intermediate Load Applications", A. D. Little, Inc., April 13, 1999.

2) IEEE Standard 762: Standard Definitions for Use in Reporting Electric Generating Units Reliability, Availability and Productivity

3) Gas Turbine World Handbook 2000

4) Annual net generation data, published by EIA

5) NERC Energy Supply and Demand 2000, April 2000.

6) RDI NewGen, July 2001. 


\section{$\underline{\text { Appendices }}$}

\subsection{Customer CTQ Descriptions}

1.2 Description of Market Segments 


\subsection{Customer CTQ Descriptions}

\begin{tabular}{|c|c|}
\hline Customer CTQs & Description \\
\hline Capital Cost (all in owners) & $\begin{array}{l}\text { Includes the gas turbine, generator, fuel supply system and } \\
\text { ancillary equipment }\end{array}$ \\
\hline Fuel Efficiency (Plant basis) & $\begin{array}{l}\text { Net Plant fuel efficiency includes the generator efficiency, fuel } \\
\text { compression and auxiliary equipment }\end{array}$ \\
\hline Planned Outage Rate (availability) & 1-(planned outage in hours)/8760 \\
\hline Starting Reliability & $\begin{array}{l}\text { Number of successful starts divided by the total number of start } \\
\text { attempts }\end{array}$ \\
\hline Operating Reliability & 1-(planned and unplanned outage in hours)/8760 \\
\hline Fast Start Time (less than 10 minutes) & Ability to go from cold engine to full power \\
\hline Fuel Flexibility: NG, Distillate & Ability to burn natural gas and D2 distillate \\
\hline Fuel Flexibility: Refinery, Biomass, Syn Gas. & Ability to burn lower quality fuels \\
\hline \multicolumn{2}{|l|}{ Tolerance for Fuel Contaminants } \\
\hline NOx Emissions Capability: $<5$ PPM & Ability to meet 5PPM NOx emissions within the gas turbine \\
\hline NOx Emissions Capability: 9 - 15 PPM & $\begin{array}{l}\text { Ability to meet } 9 \text { or } 15 \text { PPM NOx emissions within the gas } \\
\text { turbine }\end{array}$ \\
\hline NOx Emissions Capability: $\leq 25$ PPM & Ability to meet 25PPM NOx emissions within the gas turbine \\
\hline Low Technology Risk & $\begin{array}{l}\text { Technology risk posed by lack of experience with new hardware. } \\
\text { Perceived technology risk. }\end{array}$ \\
\hline Low Variable Maintenance Cost & Gas Turbine related maintenance costs. \\
\hline Fast Delivery Cycle (order to Com Opn) & Order to plant commissioning duration. \\
\hline Remote / Unattended Operation & Ability to run plant from a remote site. \\
\hline Turn-down & $\begin{array}{l}\text { The lowest power setting the gas turbine will operate efficiently } \\
\text { and with guaranteed emission limits. }\end{array}$ \\
\hline Ability to have $>400$ starts w/o penalizing life & $\begin{array}{l}\text { Designed cyclic life of the engine is high so that the yearly } \\
\text { cycling ( }>400 \text { starts/year) does not diminish the useful life of the } \\
\text { product (typically } 20 \text { years) }\end{array}$ \\
\hline $\begin{array}{l}\text { Ability to serve multiple applications includi } \\
\text { DOD, merchant plants, }\end{array}$ & \\
\hline
\end{tabular}




\subsection{Description of Market Segments}

\begin{tabular}{|c|c|}
\hline Market Segment & Description \\
\hline $\begin{array}{l}\text { Simple Cycle IPG } \\
(30-100 \mathrm{MW})\end{array}$ & $\begin{array}{l}\text { Simple Cycle Machines used by Industrial Power Generators. Gas } \\
\text { Turbines utilized are in the } 30-100 \mathrm{MW} \text { size segment. }\end{array}$ \\
\hline $\begin{array}{l}\text { Simple Cycle IPP/EUPG } \\
(30-100 \mathrm{MW})\end{array}$ & $\begin{array}{l}\text { Simple Cycle Machines used by Independent Power Producers } \\
\text { and Electric Utility Power Generators. Gas Turbines utilized are } \\
\text { in the } 30-100 \mathrm{MW} \text { size segment. Applications are limited to } \\
\text { peaking/peak shaving with yearly usage less than } 1000 \text { hours. }\end{array}$ \\
\hline $\begin{array}{l}\text { Simple Cycle IPP/EUPG } \\
(>100 \mathrm{MW})\end{array}$ & $\begin{array}{l}\text { Simple Cycle Machines used by Independent Power Producers } \\
\text { and Electric Utility Power Generators. Gas Turbines utilized are } \\
\text { >100 MW in size. Applications are limited to peaking/peak } \\
\text { shaving with yearly usage less than } 1000 \text { hours. }\end{array}$ \\
\hline $\begin{array}{l}\text { Combined Cycle IPP/EUPG } \\
(>200 \mathrm{MW})\end{array}$ & $\begin{array}{l}\text { Combined Cycle Plants greater than } 200 \mathrm{MW} \text { used by } \\
\text { Independent Power Producers (Merchant plants) and Electric } \\
\text { Utility Power Generators. Plants generally dispatched }>6000 \\
\text { hours per year. Fuel used is natural gas. }\end{array}$ \\
\hline $\begin{array}{l}\text { Combined Cycle IPP/EUPG } \\
(>150 \mathrm{MW} ;<200 \mathrm{MW})\end{array}$ & $\begin{array}{l}\text { Combined Cycle Plants greater than } 150 \text { MW but smaller than } \\
200 \mathrm{MW} \text {, used by Independent Power Producers (Merchant } \\
\text { plants) and Electric Utility Power Generators. Plants generally } \\
\text { dispatched }>6000 \text { hours per year. Fuel used is natural gas. }\end{array}$ \\
\hline $\begin{array}{l}\text { Combined Cycle } \\
(<150 \mathrm{MW})\end{array}$ & $\begin{array}{l}\text { Combined Cycle Plants smaller than } 150 \mathrm{MW} \text {, used by } \\
\text { Independent Power Producers (Merchant plants) and Electric } \\
\text { Utility Power Generators. Plants generally dispatched }>6000 \\
\text { hours per year. Fuel used is natural gas. }\end{array}$ \\
\hline IGCC - All & $\begin{array}{l}\text { Integrated Gasified Combined Cycle plants of all sizes, generally } \\
\text { using coal as fuel and being dispatched }>6000 \text { hours every year. }\end{array}$ \\
\hline $\begin{array}{l}\text { Heat Recovery } \\
(30-100 \mathrm{MW})\end{array}$ & $\begin{array}{l}\text { Combined Heat and power generation plants with gas turbine } \\
\text { output between } 30 \text { and } 100 \mathrm{MW} \text {. Typically next to a process plant } \\
\text { which is the steam host. }\end{array}$ \\
\hline $\begin{array}{l}\text { Heat Recovery } \\
(30-100 \mathrm{MW})\end{array}$ & $\begin{array}{l}\text { Combined Heat and power generation plants with gas turbine } \\
\text { output greater than } 100 \mathrm{MW} \text {. Typically next to a process plant } \\
\text { which is the steam host. }\end{array}$ \\
\hline
\end{tabular}

